\title{
A review of developments in the electrodeposition of tin
}

\section{Highlights}

- Types of aqueous electrolytes for pure tin deposits are reviewed.

- The many existing and developing applications of tin deposits are summarised.

- Emphasis is placed on versatile methanesulfonic acid electrolytes.

- The effects of bath composition (including additives) and operating conditions on deposit morphology are illustrated.

- Electrochemical studies at static and controlled flow rotating electrodes are illustrated.

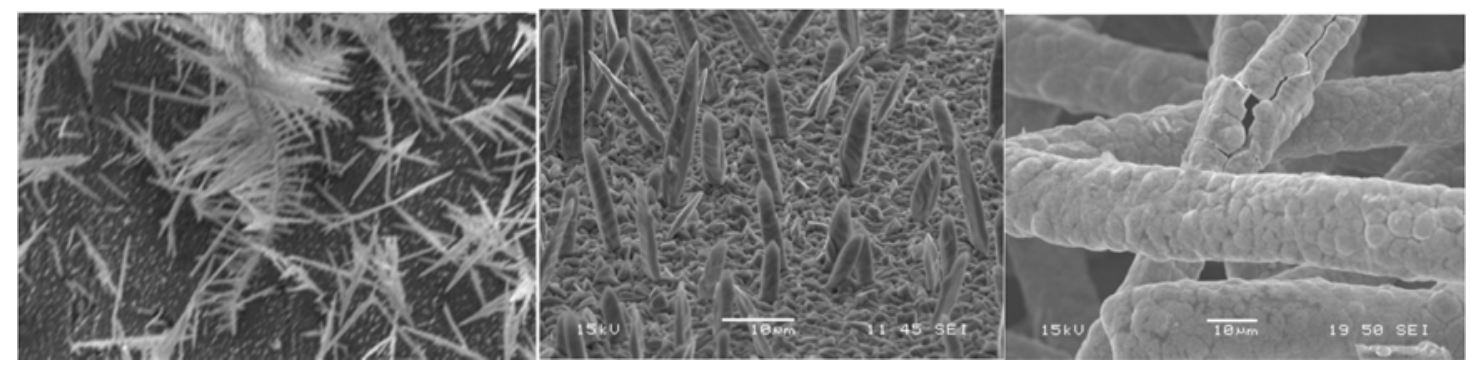


Corresponding author: F.C. Walsh

\section{Prof Frank C Walsh}

Electrochemical Engineering Laboratory

Engineering and the Environment

University of Southampton

Highfields

Southampton SO17 1BJ, UK

Tel: +44(0)2380 598752

E-mail: electro@,chemeng.fsnet.co.uk 


\title{
A review of developments in the electrodeposition of tin
}

\author{
F.C. Walsh_, ${ }^{1,}{ }^{*}$ and C.T.J. Low ${ }^{1,+}$ \\ ${ }^{1}$ Electrochemical Engineering Laboratory and Materials Engineering Research Group, \\ Engineering Sciences, University of Southampton, Highfield, Southampton, SO17 1BJ, \\ United Kingdom. \\ ${ }^{+}$Present address: WMG, Energy Innovation Centre, University of Warwick, Coventry, CV4 \\ 7AL, UK. \\ *Corresponding author. Email: F.C.Walsh@soton.ac.uk
}

\begin{abstract}
The importance of tin and its electrodeposition are summarised and the scope for plating tin is outlined. Established applications of electroplated tin include corrosion protection, electronics fabrication and cooking utensils. The past 20 years have seen developments in the science and technology of tin plating, including research into nanostructured deposits, adoption of environmentally friendly methanesulfonic acid baths and more ambitious coatings including multi-layers and composites. Our ability to tailor deposit structure and composition has been improved by newer electrolytes, pulse plating and electrolyte additives. The diversity of tin applications has extended to lithium batteries using newer structures (such as composites, multi-layers and nanostructures), electrical control (e.g., pulsed current) and relative bath/electrode movement (including the use of rotating electrodes). Electrochemical aspects of modern tin deposition are illustrated by data from the authors' laboratory which highlights the versatility of methanesulfonic acid electrolytes. A wide range of deposit morphology, colour and surface finish are possible by the use of suitable addition agents and control of electrode/electrolyte movement and operating conditions. Subject areas needing further research work are identified.
\end{abstract}

Keywords: additives, antioxidants, composite coating, hydroquinone, multi-layer, nanostructure, rotating electrode, stannate ion, stannous ion. 


\section{Contents}

1. Electrodeposition of tin

2. Recent investigations of methanesulfonic acid electrolytes for tin deposition

2.1 Voltammetry of the $\mathrm{Sn}^{2+} / \mathrm{Sn}$ couple

2.2 Tafel behaviour, mass transfer and the diffusion coefficient of $\mathrm{Sn}^{2+}$ ions

3. Nucleation and growth of tin onto copper

4. The surface microstructure of tin deposits

5. Electrolyte additives

6. Operating parameters and deposit properties

7. Applications of electrodeposited tin

8. Conclusions

9. Recommendations for further work

A review with ca. 11,500 words, 2 tables, 12 figures and 80 references 


\section{List of symbols}

c concentration of stannous ions

$\mathrm{mol} \mathrm{cm}{ }^{-3}$

$D \quad$ diffusion coefficient of $\mathrm{Sn}^{2+}$ ions

$\mathrm{cm}^{2} \mathrm{~s}^{-1}$

$E \quad$ electrode potential

$\mathrm{V}$

$d E / d t$ linear potential sweep rate

$\mathrm{V} \mathrm{s}^{-1}$

F $\quad$ Faraday constant

$\mathrm{C} \mathrm{mol}^{-1}$

j current density

$\mathrm{A} \mathrm{cm}^{-2}$

$j_{c t} \quad$ charge transfer current density for tin deposition

$\mathrm{A} \mathrm{cm}^{-2}$

$j_{L} \quad$ limiting current density for tin deposition

$\mathrm{A} \mathrm{cm}^{-2}$

$j_{\max }$ maximum current density

$\mathrm{A} \mathrm{cm}^{-2}$

$j_{p} \quad$ peak current density

$\mathrm{A} \mathrm{cm}^{-2}$

$q \quad$ electrical charge under the current $v s$. potential curve

$\mathrm{C}$

$t$ time

$\mathrm{S}$

$t_{\max }$ time corresponding to the maximum current density

$\mathrm{s}$

$z \quad$ number of electrons involved in the electrode process

dimensionless

Greek

$v \quad$ kinematic viscosity of the electrolyte

$\mathrm{cm}^{2} \mathrm{~s}^{-1}$

$\omega \quad$ electrode rotation speed

$\operatorname{rad~s}^{-1}$

\section{Abbreviations}

MSA methanesulfonic acid

PTFE polytetraflouroethylene

RCE rotating cylinder electrode

$\mathrm{RCH}$ rotating cylinder Hull

$\mathrm{RDE}$ rotating disc electrode 


\section{Electrodeposition of tin}

Tin is a soft, ductile and silvery white metal which can be deposited as a matte or bright finish. General applications of tin electroplating are listed in Table 1. 1,2 Pure tin coatings have been used to form a protective surface to resist air oxidation, to enhance corrosion resistance and to improve solderability. Bright tin coatings also provide decorative finishes that can be aesthetically pleasing even when exposed to air and moisture. The electrodeposition of tin has a long history and a good summary of its established science and technology is given in the book by Jordan, ${ }^{3}$ while the protective coatings for metals book by Gabe ${ }^{4}$ provides a useful treatment of tinplate as a metallic coating. Tin is one of the very few metals suitable for contact with foodstuffs during cooking. Pure tin and its alloys have received increasing attention as anode materials for Li-ion batteries as alternatives to graphite due to their high specific capacity and energy density.

\section{Table 1 near here.}

Electrolytes for tin deposition can be acidic or alkaline. Tin is normally deposited from divalent stannous ions, $\mathrm{Sn}^{2+}$ in an acidic bath and via tetravalent stannate ions, $\mathrm{SnO}_{4}{ }^{4-}$ in an alkaline one. The choice of bath is usually governed by the operating parameters and the required physical properties of the deposit. Important factors may include the range of applied current density, electrolyte throwing power, cathode current efficiency, surface morphology, texture and appearance, deposit uniformity, speed of deposition, use of bath additives and electrolyte stability, solubility of tin compounds, stability of electrolytes, solderability and possible reflow of deposits on heating. 
Alkaline baths are usually hydroxide based and acidic baths have sulphate or sulphonate based compositions. Alkaline baths can be operated without additives since the stannate ion appears as a soluble complex. In acidic baths, the addition of additives is required for electrolyte stability. A low maximum current density is achieved in alkaline baths and they may suffer from losses in current efficiency. ${ }^{3}$ Acidic baths can offer faster deposition rates at ambient temperature but are more complicated to maintain ${ }^{2-5}$. Their operation is largely determined by the type of additives. This review emphasises aqueous, acidic electrolytes, particularly those based on modern methanesulphonic acid, using data from the authors' laboratory to illustrate their electrochemistry and the importance of additives.

Recently, deep eutectic solvents have been studied as a new class of electrolytes for the electrodeposition of metals. Such electrolytes can be formed between a variety of quaternary ammonium salts and carboxylic acids. Their physical properties, such as viscosity, conductivity, and surface tension are similar to ambient temperature ionic liquids, rendering them suitable for developing uses in electrodeposition of tin. Abbot et al ${ }^{6}$ have described the electrolytic deposition of $\mathrm{Sn}$ and $\mathrm{Zn} / \mathrm{Sn}$ alloys from a solution of the metal chloride salts in urea and ethylene glycol/choline chloride based ionic liquids. The kinetics and thermodynamics of deposition differed from aqueous processes and different phases, compositions and morphologies were obtained for the metal coatings in various ionic liquid systems. Anodic stripping was studied by cyclic voltammetry together with compositional analysis using SEM/EDX and X-ray diffraction. The differences in electrochemical responses are rationalised in terms of the speciation of $\mathrm{Zn}$ and $\mathrm{Sn}$ chlorides in the ionic liquids that have been identified using FAB mass spectrometry. Composite coatings, containing alumina particles, could be obtained by virtue of the stable liquid suspensions. The electrodeposition of tin coatings from 
deep eutectic solvents and their subsequent whisker growth have been the subject of a recent $\mathrm{PhD}$ thesis considered in section 6.

\section{Recent investigations of methanesulfonic acid electrolytes for tin deposition}

Regardless of the type of bath, electroplated tin is soft and ductile with a relatively low melting point, $232{ }^{\circ} \mathrm{C}$ being solderable in the as-plated condition. Table 2 shows examples of recent bath formulations. ${ }^{7-16}$

Several recent investigations from our laboratory have been based on acidic electrolytes. Such baths contain sulphuric acid (molar mass: $98.1 \mathrm{~g} \mathrm{~mol}^{-1}$ ), methanesulfonic acid (molar mass: $96.1 \mathrm{~g} \mathrm{~mol}^{-1}$ ) or phenolsulfonic acid (molar mass: $174.2 \mathrm{~g} \mathrm{~mol}^{-1}$ ). Sulphuric acid is a relatively low cost electrolyte but it is an oxidant and $\mathrm{Sn}^{2+}$ oxidation can lead to precipitation of insoluble tin sulphate. This bath been restricted to low speed electrodeposition due to anode polarization at high current density. Phenolsulfonic acid is toxic and hazardous; it has a lower conductivity and is less biodegradable. In contrast, methanesulfonic acid is an organic acid, which is a versatile electrolyte for surface finishing, ${ }^{17}$ less corrosive and biodegradable, ${ }^{5}$ but more expensive, than sulphuric acid.

\section{Table 2 near here.}

As an example of tin electrodeposition from a simple, acid electrolyte in the absence of bath additives, studies by Low and Walsh ${ }^{18}$ will be considered. Tin coatings with a matte appearance could be electrodeposited onto copper from aqueous methanesulfonic acid at room temperature $(295 \mathrm{~K})$. Controlled flow conditions were also examined using a copper rotating disc electrode. In a wide-ranging study, the authors noted the electrochemical reactions of tin, 
obtained voltammetric data and considered the diffusion coefficient of stannous ion, nucleation and growth of tin on copper together with the microstructure of tin deposits. In the case of the Li-ion battery, current practice is to mix tin with a polymer binding material before being attached to the copper current collector. Electrodepositing tin directly onto copper would reduce the manufacturing steps and cost.

\subsection{Voltammetry of the $\mathrm{Sn}^{2+} / \mathrm{Sn}$ couple}

Figure 1a) shows the cyclic voltammogram recorded for an additive-free electrolyte containing $0.006 \mathrm{~mol} \mathrm{dm}^{-3} \mathrm{Sn}^{2+}$ in $1.93 \mathrm{~mol} \mathrm{dm}^{-3} \mathrm{CH}_{3} \mathrm{SO}_{3} \mathrm{H}$ at $298 \mathrm{~K}$. The electrodeposition of tin onto copper started at a potential of approximately $-0.444 \mathrm{~V} v s . \mathrm{Ag} \mid \mathrm{AgCl}$. A single cathodic current density peak was observed on the forward cathodic scan, corresponding to the reduction of $\mathrm{Sn}^{2+}$ to $\mathrm{Sn}$.

$$
\mathrm{Sn}^{2+}+2 \mathrm{e}^{-} \rightarrow \mathrm{Sn}
$$

A further rise in the cathodic current density at more negative potentials is due to the evolution of hydrogen as a secondary reaction:

$$
2 \mathrm{H}^{+}+2 \mathrm{e}^{-} \rightarrow \mathrm{H}_{2}
$$

together with some increase in the surface area of the deposit. A single anodic peak current density was observed on the reverse scan. The forward and reverse curves indicated that no significant overpotential was required for the deposition of tin onto copper. 
On reversing the potential sweep from -0.8 to $0 \mathrm{~V} v s$. $\mathrm{Ag} / \mathrm{AgCl}$, a single stripping peak was observed, confirming the two-electron oxidation step of metallic tin to stannous ion, i.e. anodic stripping of tin corresponding to the reverse of reaction (1). Voltammetry in the background electrolyte (12.5\% vol. MSA) showed neither a visible reduction nor an oxidation peak. The forward and reverse curves show no crossover, i.e. no nucleation loop or overpotential was required as the deposition of tin was thermodynamically favourable at more negative potentials on the surface of a copper substrate. The efficiency of tin oxidised from the copper substrate was estimated according to:

$$
\% \text { stripping efficiency }=\frac{q_{\text {stripping }}}{q_{\text {deposition }}} \times 100
$$

where $q$ is the electrical charge under the current $v s$. potential curve. The stripping efficiency was estimated to be in the range of 50 to $60 \%$ over a range of potential sweep rates. The low stripping efficiency is attributable to the corrosion behaviour of tin. When tin metal is dissolved to stannous ion, $\mathrm{Sn}(\mathrm{II})$, immediate oxidation to the more stable stannic ion, $\mathrm{Sn}(\mathrm{IV})$ occurs in the presence of dissolved oxygen. Tin will undergo hydrolysis in an acidic medium' stannic hydroxide can form a passive film on the electrode surface; the process may be simplified to:

$$
2 \mathrm{Sn}^{2+}+\mathrm{O}_{2}+6 \mathrm{H}_{2} \mathrm{O} \rightarrow 2 \mathrm{Sn}(\mathrm{OH})_{4}+4 \mathrm{H}^{+}
$$

The stability of the film increases with dehydration due to oxide formation:

$$
\mathrm{Sn}(\mathrm{OH})_{4} \rightarrow \mathrm{SnO}_{2} \cdot \mathrm{xH}_{2} \mathrm{O}+(2-\mathrm{x}) \mathrm{H}_{2} \mathrm{O}
$$


Figure 1b) and 1c) show voltammograms for tin deposition onto copper at a rotating disc electrode in the absence of additives. The deposition of tin was fast over a wide range of current densities, as evidenced from the mixed control region where the cathodic current density rose very steeply with respect to the electrode potential. For example, the cathodic current density reached $50 \mathrm{~mA} \mathrm{~cm}{ }^{-2}$ in an electrolyte containing $0.078 \mathrm{~mol} \mathrm{dm}^{-3} \mathrm{Sn}^{2+}$ and $1.93 \mathrm{~mol} \mathrm{dm}^{-3}$ $\mathrm{CH}_{3} \mathrm{SO}_{3} \mathrm{H}$. This characteristic is very attractive for high-speed electroplating of tin where a large current density is used to deposit tin over a short period of time. The cathodic polarization curve also showed a distinctive limiting mass transport limited by diffusion of stannous ion and increased at a higher electrode rotation speed. Co-evolution of hydrogen was shown to occur at more positive potentials and the mass transport region became shorter at higher rotation speeds and at a higher concentration of stannous ion. These trends are similar to those for deposition of tin from a commercial methanesulfonic acid electrolyte. ${ }^{19}$

\section{Figure 1 near here.}

\subsection{Tafel behaviour, mass transfer and the diffusion coefficient of $\mathrm{Sn}^{2+}$ ions}

Voltammetry showed that tin was deposited onto copper under charge transfer control, showing Tafel behaviour over a limited range of current density. The Tafel approximation was realised using pure charge transfer data extracted from the mixed control region Figure 2a). ${ }^{19}$ The Tafel slope was approximately $-20 \mathrm{mV}$ decade $^{-1}$, while Figure $2 \mathrm{~b}$ ) shows a semi-logarithmic plot of stannous ion concentration vs. the half-wave potential of the $\mathrm{Sn}^{2+} / \mathrm{Sn}$ couple. The Tafel slope was obtained from the slope as approximately $-18 \mathrm{mV}$ decade $^{-1}$, which is similar to literature values. $^{20,21}$ 
Three approaches have been used to estimate the diffusion coefficient of stannous ion in additive-free methanesulfonic acid electrolyte from voltammetry data in different electrode potential regions using the a) Randles-Sevčik (mass transport control under natural convection flow at a static electrode), b) Levich (mass transport control under full convective-diffusion, at a rotating disc electrode over a controlled range of rotation speeds) and c) Koutécky-Levich (mixed charge transfer and mass transport control at an RDE) equations: ${ }^{22-24}$

Randles-Sevčik equation

$$
\mathrm{j}_{\mathrm{p}}=2.69 \times 10^{5} \mathrm{z}^{1.5} \mathrm{D}^{0.5}\left(\frac{\mathrm{dE}}{\mathrm{dt}}\right)^{0.5} \mathrm{c}
$$

Levich equation

$$
j_{L}=0.62 z F D^{0.67} v^{-0.17} c \omega^{0.5}
$$

Koutécky-Levich equation

$$
\frac{1}{j}=\frac{1}{j_{c t}}+\frac{1}{0.62 z F D^{2 / 3} v^{-1 / 6} c \omega^{1 / 2}}
$$

where $j_{p}$ is the peak current density, $z$ is the number of electrons involved in the electrode process, $D$ is the diffusion coefficient of $\mathrm{Sn}^{2+}, d E / d t$ is the linear potential sweep rate, $c$ is the concentration of stannous ions, $j_{L}$ is the limiting current density for tin deposition, $v$ is the kinematic viscosity of the electrolyte, $\omega$ is the electrode rotation speed and $j_{c t}$ is the pure charge transfer current density for tin deposition.

\section{Figure 3 near here.}

Figures 3a) to d) show plots derived from the voltammetry. The Randles-Sevčik equation uses data from the cyclic voltammogram at a static electrode in a stationary electrolyte. This 
equation assumes a reversible reaction for $\mathrm{Sn}^{2+}$ reduction to $\mathrm{Sn}$ while the Levich equation assumes complete mass transport control of tin deposition at a hydrodynamically smooth rotating disc electrode. The Koutécky-Levich equation uses data from the mixed control region and does not require an estimation of the limiting current density for the data analysis. More information about these equations and their use is available elsewhere in the electrochemical literature. $^{22-24}$

Electrochemical data the $\mathrm{Sn}^{2+} / \mathrm{Sn}$ redox couple in an additive-free electrolyte followed equations (1) to (3). The estimated diffusion coefficient of $\mathrm{Sn}^{2+}$ from the three approaches showed slight differences. Using cyclic voltammetry data (from the effect of potential sweep rate under static from controlled flow conditions, it was $6.2 \pm 0.6 \times 10^{-6} \mathrm{~cm}^{2} \mathrm{~s}^{-1}$ (from the effect of concentration of stannous ion) and $4.0 \pm 0.4 \times 10^{-6} \mathrm{~cm}^{2} \mathrm{~s}^{-1}$ (on the effect of electrode rotation speed). Using data from the mixed control region, the diffusion coefficient of $\mathrm{Sn}^{2+}$ was approximately $4.4 \pm 0.4 \times 10^{-6} \mathrm{~cm}^{2} \mathrm{~s}^{-1}$. The authors prefer the well-defined, steady state RDE data, giving a diffusion coefficient of stannous ions as $6.2 \pm 0.6 \times 10^{-6} \mathrm{~cm}^{2} \mathrm{~s}^{-1}$. The literature reports a diffusion coefficient for $\mathrm{Sn}^{2+}$ as high as $9.8 \times 10^{-6} \mathrm{~cm}^{2} \mathrm{~s}^{-1}$ in an electrolyte containing $0.05 \mathrm{~mol} \mathrm{dm}^{-2} \mathrm{Sn}^{2+}$ in $2 \mathrm{~mol} \mathrm{dm}^{-3} \mathrm{CH}_{3} \mathrm{SO}_{3} \mathrm{H} .{ }^{25}$

\section{Nucleation and growth of tin on copper}

Current transient curves for the electrodeposition of tin onto a copper, in the absence of additives are shown in Figure 4(a). All curves started with a momentary decrease in the current density due to double layer charging. ${ }^{21}$ At $-0.454 \mathrm{~V}$ vs. $\mathrm{Ag} \mid \mathrm{AgCl}$, the current density rose sharply due to the formation of tin nuclei on the copper surface. The deposition of tin was found to be diffusion limited as evidenced by the steady-state current density at longer times. 
This trend followed the Cottrell equation relating to natural convection at a stationary electrode. ${ }^{25,27}$ A linear relationship was found on a semilogarithmic plot of current density vs. time in Figure 4b) which suggests tin deposition onto copper proceeded through a rapid cluster nucleation with a subsequent diffusion-limited growth. The nucleation process of tin onto copper was analysed using data from the rising part of the experimental current transient curve compared with dimensionless theoretical curves for both instantaneous and progressive nucleation according to the Scharifker-Hills equations ${ }^{27-32}$ in Figure 4c). The current transient closely matched the instantaneous 3-D nucleation-growth model: ${ }^{32-36}$

$$
\left(\frac{j}{j_{\max }}\right)=\frac{1.9542}{t / t_{\max }}\left[1-\exp \left(-1.2546\left(\frac{t}{t_{\max }}\right)\right)\right]^{2}
$$

(9)

$$
j_{\max }^{2} t_{\max }=0.1629 z^{2} F^{2} c_{S n^{2+}}^{2} D
$$

where $j_{\max }$ and $t_{\max }$ is at the maximum point in Figure 4a). Differentiating the logarithmic form of equation (10) with respect to potential gives Figure 4d), which shows a linear dependence of the $\log \left(j_{\max }\right)$ and $\log \left(t_{\max }\right) v s$. potential were obtained. $\frac{\partial \log j_{\max }}{\partial E}$ and $\frac{\partial \log t_{\max }}{\partial E}$ had values of -44 decade $\mathrm{mV}^{-1}$ and -92 decade $\mathrm{mV}^{-1}$, respectively, which are consistent with reaction (1). The simplest interpretation of the model is that hemispherical tin nuclei were created simultaneously and grew randomly on the copper electrode surface via a diffusion controlled process. 


\section{The surface microstructure of tin deposits}

Figures 5a) to d) show the surface microstructure of tin deposited onto copper at constant potential. At an electrode potential from -0.45 to $-0.65 \mathrm{~V} v s$. $\mathrm{Ag} \mid \mathrm{AgCl}$, a matte, non-dendritic tin deposit was deposited. At more negative potentials, from -0.75 to $-0.95 \mathrm{~V} v s$. $\mathrm{Ag} \mid \mathrm{AgCl}$, the tin deposit showed some porosity, due to co-evolution of hydrogen and needle-like dendrites were observed. At even more negative potentials, the dendrites grew into tree-like branches, from 100 to $200 \mu \mathrm{m}$ long.

\section{Figure 5 near here.}

Voltammetry studies showed a number of features:

1. matte tin coatings were electrodeposited on copper from additive-free acidic methanesulfonate electrolyte using a rotating disc electrode in an electrolyte containing 0.006 to $0.078 \mathrm{~mol} \mathrm{dm}^{-3} \mathrm{Sn}^{2+}$ in $1.93 \mathrm{~mol} \mathrm{dm}^{-3} \mathrm{CH}_{3} \mathrm{SO}_{3} \mathrm{H}$ at $295 \mathrm{~K}$;

2. electrodeposition of tin onto copper occurred readily over a narrow potential range of charge transfer and mixed control. A well-defined mass transport controlled limiting current and coevolution of hydrogen were seen to be dependent on the stannous ion concentration and rotating disc speed;

3. the Levich, Koutécky-Levich and Randles-Sevcik equations were used to evaluate the electrodeposition of Sn using different voltammetric data;

4. no significant overpotential was required for tin deposition;

5. the tin deposits were compact, non-dendritic and adherent to the copper substrate; they followed a diffusion controlled process via an instantaneous three-dimensional nucleation 
growth mechanism. Needle-like dendrites were obtained at potentials where co-evolution of hydrogen occurred.

Studies by the authors at the University of Southampton resulted in a series of publications in 2008 which considered the voltammetry of tin deposition and the deposit morphology from methanesulfonic acid solutions in more detail. The first paper considered a mixed sulfatemethanesulfonate acid electrolyte. ${ }^{37}$ The deposition of tin onto copper and the stripping of tin) from an electrolyte containing $0.014 \mathrm{~mol} \mathrm{dm}^{-3} \mathrm{SnSO}_{4}$ in $12.5 \%$ vol. methanesufonic acid at $295 \mathrm{~K}$ was studied using cyclic voltammetry at a static disc and linear sweep voltammetry at a rotating disc electrode. Overall, the electrode kinetics proved similar to those in pure acid methanesulfonate baths. The diffusion coefficient of stannous ion was found to be $6.5 \pm 0.6 \mathrm{x}$ $10^{-6} \mathrm{~cm}^{2} \mathrm{~s}^{-1}$ using linear sweep voltammetry at an RDE.

Figure 6 near here.

A second paper focused on the importance of a hydroquinone antioxidant ${ }^{38}$ in baths containing $0.014 \mathrm{~mol} \mathrm{dm}^{-3} \mathrm{SnSO}_{4}$ and $12.5 \%$ vol. methanesulfonic acid $\left(1.93 \mathrm{~mol} \mathrm{dm}^{-3} \mathrm{MSA}\right)$ at $296 \mathrm{~K}$. The Levich and Randles-Sevčik equations were used to evaluate the mass transport characteristics of stannous ions at various potential sweep rates, electrode rotation speeds and hydroquinone concentrations. The diffusion coefficient of stannous ions was found to be $7.7 \pm 0.5 \times 10^{-6} \mathrm{~cm}^{2} \mathrm{~s}^{-1}$. Tin was electrodeposited onto a copper surface over a narrow potential range of the charge transfer and mixed control with a well-defined mass transport controlled region. Voltammetry showed a negligible charge transfer overpotential. Under static electrode conditions, a single reduction and oxidation peak were observed in the absence and presence of hydroquinone. At a rotating disc electrode, a single limiting plateau was seen, corresponding 
to the two electron reduction of stannous ions to metallic tin. Both the region of complete mass transport control and the potential for the onset of hydrogen evolution were dependent on the electrode rotation speed and hydroquinone concentration. When the concentration ratio of hydroquinone to stannous ion was 0.36 and 3.6, the complete mass transport controlled region was lengthened and the hydrogen evolution was shifted to more electronegative potentials. Electrolyte stability was monitored with storage time via changes in the deposition charge and stripping efficiency together with the peak and limiting current densities. In the absence of hydroquinone, a significant loss in these variables is observed. The addition of hydroquinone to the electrolyte served to significantly reduce the rate of stannous ion oxidation to stannic ion. The electrolyte stability against storage hours was monitored via changes in the deposition charge and stripping efficiency. Tin was electrodeposited at $-0.5 \mathrm{~V} v \mathrm{~s}$. $\mathrm{Ag} / \mathrm{AgCl}$ for 30 seconds and then striped from $-0.5 \mathrm{~V}$ to $0 \mathrm{~V} v s$. $\mathrm{Ag} / \mathrm{AgCl}$. Figure $6 \mathrm{a}$ ) shows the charge consumed with storage time from 0 to 512 hours. In the absence of hydroquinone, only $37 \%$ of the original deposition charge was maintained after 512 hours. When hydroquinone was present, the deposition charge remained similar for the duration of studies. The addition of hydroquinone as an antioxidant minimized the oxidation rate of stannous to stannic ions. The deposition charge was lower at a high hydroquinone concentration $\left(0.5 \mathrm{~mol} \mathrm{dm}^{-3}\right)$, than at lower $(0.005$ and $0.05 \mathrm{~mol} \mathrm{dm}^{-3}$ ) hydroquinone levels. The corresponding stripping efficiency is plotted in Figure 6b). In the absence of hydroquinone antioxidant, the stripping efficiency decreased with storage time. With sufficient hydroquinone in the electrolyte, it remained constant at approximately $83 \%$ with storage time.

Figure 7 near here. 
The loss in the deposition charge and stripping efficiency for tin deposition was examined by cyclic voltammetry. Figure 7a) shows the deposition charge consumed at various sweep rate, in the absence of hydroquinone. The tin was electrodeposited during the potential sweep from $0 \mathrm{~V}$ to $-0.65 \mathrm{~V} v s . \mathrm{Ag} / \mathrm{AgCl}$. The deposition charge decreased with storage time and sweep rate in a logarithmic relationship. Figure 7b) shows the stripping efficiency decreased with storage time but increased to a steady state at increasing sweep rate. At a lower sweep rate, thicker tin deposits were formed. The stripping efficiency obtained from cyclic voltammetry was smaller than that obtained at a constant tin deposition potential. Figure 6b) showed that it dropped from $79 \%$ to $73 \%$ after 512 hours; while Figure 7 a) showed that the stripping efficiency dropped from $53 \%$ to $35 \%$ after 512 hours. This is attributable to the different techniques used to form the deposits in the presence or absence of an antioxidant in the electrolyte. At a constant deposition potential, tin deposits were uniformly formed throughout the experiment. For tin deposits obtained from the cyclic voltammetry, the morphology changed as the potential became more electronegative and non-uniform deposits were obtained at longer times.

Figure 8a) shows the linear sweep voltammetry of tin electrodeposited at control rotation speeds. The electrolyte was $0.014 \mathrm{~mol} \mathrm{dm}^{-3} \mathrm{SnSO}_{4}$ and $12.5 \%$ vol. methanesulfonic acid without hydroquinone. Electrode rotation rates from 200 to $4800 \mathrm{rpm}$ were investigated. Voltammetry in the background electrolyte was also performed. The electrode potential was swept from 0 to $-1.0 \mathrm{~V} v s$. $\mathrm{Ag} / \mathrm{AgCl}$ at $16 \mathrm{mV} \mathrm{s}^{-1}$. Regions of charge transfer, mixed (charge transfer and mass transport) and mass transport control were clearly defined. As the rotation speeds increased, the current density for the mixed control region increased and the potential window for complete mass transport control was narrowed leading to earlier hydrogen evolution. 
Figure 9a) shows the voltammetrogram of tin electrodeposited in the presence of various hydroquinone concentrations. The addition of hydroquinone to the electrolyte showed a single limiting plateau for tin deposition from an acid methanesulfonate electrolyte. The presence of hydroquinone lengthened the complete mass transport control region and suppressed the hydrogen evolution to more electronegative potential. It also reduced the limiting current density, which may be associated with the adsorption of hydroquinone onto the electrode surface. Under complete mass transport controlled conditions, the Levich equation relates the limiting current density to the electrolyte conditions and electrode rotation speed ${ }^{22-24}$.

Figure $9 b$ ) shows the limiting current density with square root of electrode rotation speed at various hydroquinone concentrations. The diffusion coefficient of stannous ions was extracted from the slope and was found to be $3.8,6.0,9.9,4.4 \pm 0.5 \times 10^{-6} \mathrm{~cm}^{2} \mathrm{~s}^{-1}$ for $0,0.005,0.05$ and $0.5 \mathrm{~mol} \mathrm{dm} \mathrm{m}^{-3}$ hydroquinone concentrations, respectively.

\section{Figure 9 near here.}

Figure 10 shows a similar relationship where the addition of hydroquinone to the electrolyte increased the region of complete mass transport control and shifted the onset of hydrogen evolution to more electronegative potential. The potential became more positive with the electrode rotation speed but remained constant at saturated hydroquinone concentration.

Figure 10b) shows a similar relationship where the addition of hydroquinone to the electrolyte shifted the onset of hydrogen evolution to more electronegative potential. The potential 
became more positive with the electrode rotation speed but remained constant at saturated hydroquinone concentration.

\section{Figure 10 near here.}

The change of limiting current density with storage time is plotted in Figure 11a) in the absence of hydroquinone and in Figure 11b) with $0.005 \mathrm{~mol} \mathrm{dm}^{-3}$ hydroquinone in the electrolyte. In the absence of hydroquinone, the limiting current density reduced significantly over the duration of studies. Figure 11c) showed the loss in the limiting current density with logarithmic of storage time. After 512 hours, approximately $67 \%$ loss in the limiting current density was observed in baths without hydroquinone. For $0.005,0.05$ and $0.5 \mathrm{~mol} \mathrm{dm}^{-3}$ hydroquinone additions to the electrolyte, only a 9 to $13 \%$ loss was found after 512 hours.

\section{Figure 11 near here.}

A third paper looked in detail at the effect of a perfluorinated cationic surfactant, DuPont

ForaFac ${ }^{\circledR} 1098 .{ }^{39}$ The electrolyte was $0.014 \mathrm{~mol} \mathrm{dm}^{-3} \mathrm{SnSO}_{4}, 0.005 \mathrm{~mol} \mathrm{dm}^{-3}$ hydroquinone and $12.5 \%$ vol. (1.93 mol dm $\left.{ }^{-3}\right)$ methanesulfonic acid at $296 \mathrm{~K}$, containing controlled concentrations (12 to $2.4 \%$ vol.) of the surfactant.

\section{Figure 12 near here.}

Figure 12 shows the effect of the surfactant on the voltammetry of tin deposition. The dependence of deposition peak current density with the square root of potential sweep rate was analysed via the Randles-Sevčik equation. Figure 12a) shows that a linear dependence was 
obtained in the absence of surfactant, but this changed to a second order polynomial relationship when surfactant was added to the electrolyte. Figure 12b) shows the percentage loss in the deposition peak current density. When surfactant was added to the electrolyte, it reduced to about 16 to $22 \%$ for 0.12 to $2.4 \%$ vol. DF. The decrease in the deposition charge occurs due to absorption of surfactant on the electrode surface reducing active sites available for the formation of tin deposits. The deposition charge passed during a potential sweep from 0 to $0.65 \mathrm{~V} v s . \mathrm{Ag} \mid \mathrm{AgCl}$ is shown in Figure 12c) as a function of potential sweep rate. The effects of the additive can be summarised.

1. Levich and Randles-Sevčik equations were used to evaluate the mass transport characteristics of stannous ions at various potential sweep rates, electrode rotation speeds and surfactant concentrations. Changes in the peak current density (with a static electrolyte) and limiting current density (at controlled RDE speeds) revealed a linear relationship between peak current density and the square root of potential sweep rate in the absence of surfactant but a non-linear relationship when surfactant was added to the electrolyte.

2. Electrodeposition of tin onto a copper surface started at about $-0.445 \mathrm{~V} v s$. $\mathrm{Ag} \mid \mathrm{AgCl}$ with or without surfactant in the electrolyte, at stationary and control flow conditions. In the absence of surfactant, no overpotential was required for the deposition of tin when a copper substrate was used. In the presence of surfactant, the nucleation of anodic current density, however, was dependent on the end potential and the presence of adequate solution agitation, an overpotential of approximately $-100 \mathrm{mV}$ being required.

3. The role of surfactant during tin deposition was found to be potential and flow-dependent, from an analysis of surface coverage from the voltammetry. The adsorption orientation of surfactant onto the electrode surface could be altered with possible desorption at more electronegative potential. Its presence hindered hydrogen evolution and accounted for the 
reduction in peak and limiting current density as well as the lower charge passed from the cyclic voltammetry and potentiostatic control of deposition.

\section{Electrolyte additives and operating parameters}

In industry, tin is rarely electrodeposited in the absence of bath additives. Proprietary mixtures of organic additives are commonly used to produce good quality coatings. The choice of additives is often dependent upon the bath composition and required properties. Additives used in acid baths are different from alkaline baths, since stannous ions are susceptible to oxidation in acidic baths while stannate ions are present as complexing ions in alkaline baths. Examples of the role of electrolyte additives in acidic baths are given in Table 3.

\section{Table 3 near here.}

Electrodeposition of tin from acidic baths is usually a simple process with little activation polarization. Compared to alkaline baths, a doubling in the amount of electricity is required to yield the same amount of deposit because tin appears in the divalent state in acidic baths but in the tetravalent one in alkaline baths. In the acidic baths, a single reduction and oxidation peak will be observed with cyclic voltammetry, under stationary conditions. An abrupt increase in the current density at the charge transfer region usually signifies tin deposition onto the substrate. When additives present in the baths, the electrode is usually polarised such that tin deposition initiates at a more negative potential due to adsorption of additives on the deposit surface.

Additives may include aromatic carbonyl compounds, amine derivatives, aromatic heterocyclic aldehydes, aromatic ketones and others. ${ }^{15}$ The development of these additives is largely 
empirical despite their importance to the morphology of tin deposits. Additives may include surfactants, oxidation inhibitors and grain refiner/brighteners. Surfactants are used to promote polarizing effects on the electrode reactions; oxidation inhibitors are added to reduce the formation rate of stannic ions thus lowering sludge precipitation in the electrolyte and grain refiner/brighteners are added to produce whisker-free or dendritic-free and matte or bright deposits.

Tin has a standard reduction potential of approximately $-0.14 \mathrm{~V}$ vs. SHE and since the reduction potential of stannic to stannous ions is approximately $+0.15 \mathrm{~V} v$ s. SHE, stannous tin solutions can be quite unstable. If exposed to the atmosphere for any appreciable length of time, the tin based solutions can be easily oxidized to stannic ions, particularly in the presence dissolved oxygen in the solution.

The formation of sludge from stannic ion precipitation is undesirable since it can contaminate deposits and the formulation of tin electroplating baths involves antioxidants which retard the oxidation of stannous to stannic tin. Effective antioxidants commonly used include naphtholsulfonic acid, hydrazine, pyrogallol, phenolsulfonic acid and cresolsulfonic acid. Others include catechol, phenidone, morin hydrate (2',3,4',5,7-pentahydroxyflavone), and vanadium pentoxide. ${ }^{40}$ The oxidation inhibitors lower oxygen levels or slow reaction rates between oxygen and stannous ions. ${ }^{3,41,42}$ Table 4 shows examples of well-known antioxidants and their likely chemical reaction with oxygen.

Table 4 near here. 
Considerable efforts have been directed to finding suitable additives for tin electroplating baths. Organic additives such as a surfactant, ${ }^{43-45}$ an aromatic carbonyl compound ${ }^{46}$ and an aminealdehyde reaction product. ${ }^{47}$ Electrodeposition of tin from sulphuric acid baths containing formaldehyde, propionaldehyde and benzadehyde showed that a significant overpotential was required. It was reported that the electrode was most polarised in the presence of benzaldehyde, at approximately $-1.1 \mathrm{~V} v s . \mathrm{Sn} \mid \mathrm{Sn}^{2+}$, an intermediate for formaldehyde and propionaldehyde, at approximately $-0.55 \mathrm{~V} v s . \mathrm{Sn} \mid \mathrm{Sn}^{2+}$ and no polarization was required for baths without additives. It was also reported that aldehyde type additives that has a hydrophobic group, for example benzaldehyde, are more easily absorbed onto the electrode surface. Hydrophilic additives such as propionaldehyde and benzaldehyde showed a higher diffusion coefficient and limiting current density. The absorption of organic molecules on the electrode blocked the active sites for deposition which impeded the charge transfer reaction and involved an increased overpotential for electrodeposition. ${ }^{13}$

Glycol additives have been widely used in tin electroplating baths, including polyethlene glycol (PEG) and polypropylene glycol (PPG). Electrodeposition of tin from methanesulfonic acid baths containing polyethlene glycol, polypropylene glycol and phenolphthalein has shown that the PPG molecule is likely to enhance the adsorption of PEG on the electrode surface and phenolphthalein helped to produce a smooth and matte surface finishes. ${ }^{46}$ The adsorption of these additives minimized the hydrogen evolution reaction rate, thus the grain sizes and surface roughness of the deposits are reduced.

Electrodeposition of tin from sulphuric acid in the presence of synthanol, formalin and benzyl alcohol has also been studied. It was reported that the double layer capacitance was reduced from 32 to $8 \mu \mathrm{F} \mathrm{cm}^{-2}$ in the presence of these additives. Lustrous coatings with fine crystalline 
structure and good adherence were obtained. ${ }^{14,48}$ The addition of coumarin (benzopyran-2one), often used to promote lustrous and smooth coatings in nickel plating, was also studied on tin deposition. As the solubility of coumarin was $2 \mathrm{~g} \mathrm{dm}^{-3}$, it was added into the bath, using a porous polypropylene bag, at a concentration exceeding its solubility. In this fashion, coumarin was able to self-regulate its concentration in the bath; its consumption being $0.01 \mathrm{~g} \mathrm{~A}^{-1} \mathrm{~h}^{-1} \cdot 43$

The addition of an octylphenol ethoxylate surfactant, Triton X-102 to tin electrolytes from a mixture of sulphuric and phenolsulfonic acid showed that the additive shifted the cell voltage from $0.4 \mathrm{~V}\left(0.035 \mathrm{~g} \mathrm{dm}^{-3}\right.$ additive $)$ to $0.7 \mathrm{~V}\left(1 \mathrm{~g} \mathrm{dm}^{-3}\right.$ additive $) .{ }^{43}$ The increase in polarisation becomes detrimental as more energy is required for deposition. When the additive level was below its critical micelle concentration $\left(0.2\right.$ to $\left.0.3 \mathrm{~g} \mathrm{dm}^{-3}\right)$, the active sites for preferential growth of tin deposits were blocked. At concentrations above the critical micelles concentration, the additive formed micelles and the electrode surface became blocked by a membrane-like layer. This hindered mass transport and a higher current density was required to achieve a homogenous and dendrite-free tin deposit. It has also been reported that voltage oscillations may be an indication of irregular growth of tin deposits such as dendrites. ${ }^{43}$

The effect of aromatic ketones (benzalacetone, BA and benzophenone, BP) and N,Nbis(polyoxyethylene)octadecylamines, on tin deposition from sulphuric acid has been studied. The reduction potential of tin was found to be approximately $-0.45 \mathrm{~V} v s$. SCE and the limiting current density changed by bath additives; benzylacetone acted as a leveller, benzophenone acted as a grain refiner and the amines induced uniform tin deposits. The combination of these three additives has shown a synergistic effect on tin deposits. ${ }^{8}$ The synergistic effects of organic additives (t-octylphenoxyethoxy ethanol, TX100, phenyl-2-butenalimine, AAPR and formaldehyde) have also been studied. When the additives are added solely or in combination, 
the deposition mechanism altered and hemispherical nuclei are formed on the electrode surface. The electrocrystallisation changed from instantaneous to progressive 3-D growth control. ${ }^{16}$

The effect of ethoxylated $\alpha$-naphtholsulfonic acid on tin deposition has also been studied using phenolsulfonic acid as the supporting electrolyte. The naphtholsulfonic was reported to form a compact structure at the electrode surface and affected the mass transport control of tin deposition (the limiting current density reduced with naphtholsulfonic concentration). The molecules remained stable and fully adsorbed on the electrode surface even at more negative potentials. The presence of the naphtholsulfonic acid also slowed down the hydrogen evolution reaction and reduced the impact of tin dissolution. ${ }^{11}$

The effect of gelatin on tin deposition from sulphuric acid has been studied in some detail. The potential for hydrogen evolution was shifted to more negative values; approximately $0.3 \mathrm{~V}$ in the presence of $2 \mathrm{~g} \mathrm{dm}^{3}$ gelatin and the limiting current density was lowered. ${ }^{14}$ The adsorption of polyoxyethylene lauryl ether, POELE in the tin deposition from sulphuric acid was investigated. The additive was reported to adsorb onto the tin deposit at the beginning of deposition, then suppressed subsequent tin deposition on high energy sites thus leading to a smoother surface. Fourier transform infrared spectrometry (FTIR) was used to identify adsorption of the surfactant. ${ }^{49}$

A recent voltammetry and electrochemical impedance spectroscopy study by Chinese workers has considered electrolyte additive effects on tin electrodeposition from acid sulfate electrolytes. In the absence of additives, tin coatings are rough, and the tin electrodepositing is a single-step reduction process accompanied by hydrogen evolution. The addition of tartaric acid produced a slight reduction in the peak current of stannous reduction and was claimed to 
improve the bath stability. Both benzylidene acetone and polyoxyethylene octylphenol ether hindered stannous ion reduction and suppressed the hydrogen gas evolution. Formaldehyde slightly decreased the peak current density of stannous ion reduction and served as an auxiliary brightener in the acid sulfate bath. The presence of mixed additives produced a significantly smoother and denser tin coating having the (112) crystal face as the dominant and preferred orientation of the tin deposits. ${ }^{50}$

The effect of $\left(<500 \mathrm{mg} \mathrm{dm}^{-3}\right)$ chloride ions on the thickness, surface roughness, microstructure and composition of tin deposits from a methanesulfonic acid bath have been studied. It was reported that the presence of $100 \mathrm{mg} \mathrm{dm}^{-3}$ chloride ions in the electroplating baths has a negligible effect on stannous ion reduction. ${ }^{51}$ The chloride ion had little effect on the thickness at a given current density and the surface morphology is similar. X-ray photoelectron spectroscopy showed that no residual chloride was attached to the surface of matte tin deposits. Oxide was detected on the surface in the presence or absence of chloride ions in the bath. ${ }^{51}$

Non-ionic ethoxylated compounds, such as the Triton X series of surfactants, have proven popular for tin deposition. For example, the surfactant has helped to give a uniform, adherent and semi-bright tin or a uniform, adherent and semi bright tin deposit ${ }^{43}$ but below $0.12 \mathrm{~g} \mathrm{dm}$ ${ }^{3}$, the surfactant had no effect on the quality of tin deposit and dendrites were formed, Triton $\mathrm{X}-100$ can result in deposition of needle-like structures of tin. ${ }^{53}$

\section{Operating parameters and deposit properties}

Various factors that influence the properties of deposits have also been studied, including the effect of electrolyte, current density, temperature, brighteners, substrates and flow conditions has been reported. The thickness and grain structure of the electroplated coatings have been 
discussed. Many investigations have focussed on producing good quality tin coatings that are pore-free, with no whisker formation from stable baths capable of prolonged storage. The operating variables are often interrelated and relationship can be obtained with systematic quantitative studies. Correlation was found with plating efficiency, electrode rotation speed, current density, temperature and surface morphology. ${ }^{54}$ Another example is the study of the surface microstructure of tin deposited from tin chloride and tetrapotassium pyrophosphate as a complexing agent. While the current density affected surface morphology and the solution $\mathrm{pH}$ affected the crystal orientation of tin deposits, the current density and $\mathrm{pH}$ had no significant effect on the grain size. ${ }^{55}$

Other investigations include the control of electroplating parameters to engender tin electrodeposit with a microstructure and grain orientation that were inherently resistant to whisker growth ${ }^{56}$. It is generally postulated that deposits with columnar grain structures are more susceptible to whisker growth than those with equiaxed grain structures ${ }^{57}$. In another study, a relationship of deposition current density on whisker growth was observed under thermal cycling ${ }^{58}$; elsewhere, whisker growth on pulse electrodeposited tin increased with increasing deposition current density due to changes in the grain structure and orientation of the deposit ${ }^{59}$.

In kinetic studies, potentiostatic and galvanostatic methods are frequently used. Nucleation and growth on carbon and steel have been investigated. In many cases, the surface microstructure, nucleation and growth control were transformed with increasing overpotential. On a vitreous carbon substrate, tin deposition from sulphuric acid without additives occurs via an instantaneous nucleation and three dimensional growth limited by diffusion. ${ }^{61}$ It was reported that tin deposition occurred more preferentially at step edges, dislocations and defects on the 
carbon substrates. Scanning tunnelling (STM) scanning electron (SEM) and atomic force microscopy (AFM) have been used for surface observation and have provided information about nuclei formation and topography of the crystallites. Chronoamperometric techniques have also been used to understand the kinetics of tin deposition. ${ }^{62}$

Cyclic voltammetry of tin deposited from sulphuric acid containing gluconate as a complexing agent was carried out. In a highly acidic bath, the voltammetry remains similar but at $\mathrm{pH} 4$ the reduction potential shifted from $-0.5 \mathrm{~V}$ to $-0.7 \mathrm{~V} v s$. $\mathrm{Ag} \mid \mathrm{AgCl}$. The potential for hydrogen evolution also shifted to a negative potential. It was reported that the addition of gluconate favoured the instantaneous nucleation process with 2-D growth control and has lowered the growth rate of tetragonal tin crystallites. At higher gluconate concentration, the deposition mechanism becomes a progressive nucleation process with 2 -D growth control. ${ }^{63}$ Cyclic voltammetry of a tin electrode in sodium citrate at $\mathrm{pH} 6$ is studied, ${ }^{62}$ in $0.5 \mathrm{dm}^{-3}$ bicarbonate ${ }^{60}$ and in a carbonate-bicarbonate mixture at $\mathrm{pH} 8.9 .{ }^{66}$

In addition to cyclic voltammetry, potentiostatic and galvanostatic techniques are used in the study of the effects of organic additives on tin deposition and surface enhanced Raman spectroscopy technique has also been explored. This technique uses a vibrational spectroscopy method (SERS) and is very surface selective. It has been used to understand the adsorbed species, their orientation on the electrode surface and the adsorption strength. For example, Triton X-100 adsorbed on the electrode surface in a wide range of potential where a hydrophobic head group serves as an anchor of the molecule and at negative potential, the hydrophilic tail turned towards the electrode surface. The adsorption of Triton X-100, PEG and phenolphthalein has been studied using the SERS method. ${ }^{9}$ 
Electrodeposition of tin deposits containing particulate inclusions has received little attention. An example of tin composite coating is tin-titanium-niobium carbonitride Chevrel phase particles, such phases, e.g. $\mathrm{M}_{\mathrm{x}} \mathrm{Mo}_{6} \mathrm{~T}_{8}(\mathrm{M}=$ metal, $\mathrm{T}=\mathrm{S}$, Se, Te $)$ being superconducting compounds. The incorporation of the particles into a tin matrix during electrodeposition has been achieved with the use of cationic surfactants such as alkylbenzyltrimethylammonium chloride and alkyldiethanolbenzylammonium chloride. The composite coating could contain 10 to $88 \%$ wt. particles and had favourable superconductivity, corrosion resistance and solderability. The pores and cracks in the deposits were eliminated by thermal treatment at 260 to $310{ }^{\circ} \mathrm{C}$ for 4 to 40 hours. ${ }^{67} \mathrm{~A}$ nanostructured tin matrix containing mesoporous titanium dioxide has also been prepared. ${ }^{68}$

The electrochemical dissolution of tin in a methanesulfonic acid bath has recently been studied. The rate of tin dissolution was determined by the acidic concentration, oxygen concentration, intensity of flow condition and bath temperature. ${ }^{69}$ Laser Raman spectroscopy and infrared reflection absorption spectroscopy have been used to identify the surface film of tin in three different conditions; $0.1 \mathrm{~mol} \mathrm{dm}^{-3} \mathrm{NaOH}, 0.15 \mathrm{~mol} \mathrm{dm}^{-3} \mathrm{NaCl}$ and $\mathrm{pH} 4.3$ phosphate buffer solutions. Cyclic voltammetry and spectroscopy methods were shown to be successful in identifying the corrosion films generated at different potentials in the aqueous solutions. ${ }^{70}$

Electrochemical recovery of tin has been studied using a fluidised bed electrochemical cell that contains a mesh electrode and inert glass beads. This introduced a high degree of turbulence in the cell for improved mass transport control. ${ }^{69}$ A nitric acid stripping solution was used in the electrochemical recovery of tin from waste solutions of printed circuit boards. ${ }^{72}$ Recovery of tin using a rotating cylinder electrode of expanded metal was also studied ${ }^{41}$ and has allowed 
successful tin recovery. For example, at $-0.65 \mathrm{~V} v s$. SCE and $500 \mathrm{rpm}$, the tin concentration decreased from 393 to $94 \mathrm{mg} \mathrm{dm}^{-3}$ after 30 minutes electrolysis.

\section{Applications of electrodeposited tin}

Tin coatings are widely used in the production of food containers, automotive pistons and pump parts, coatings on copper and steel strip and wires, in the electrical and electronics components and printed wiring boards. Tin coatings are used extensively in the food processing industry since they are non-toxic, ductile, and corrosion resistant. The excellent ductility of tin metal allows the coated substrate (metal or non-metal) to be formed into a variety of shapes without damage to the coating. Thicker deposits up to $30 \mu \mathrm{m}$ are generally required in food processing equipment and shipping containers to prevent corrosion. When tin is used to protect steel, it is very important that the coating is free from through pores to prevent severe localised galvanic corrosion. Tin coating in the electronics industry can protect the base metal, such as copper, from oxidation. Tin coating can also be a replacement for tin-lead and nickel layers. Thick deposits, e.g., 50-250 $\mu \mathrm{m}$ are usually used for engineering applications such as on pump parts and piston rings in the automotive industry since they can confer anti-galling properties.

Recent investigations have been directed to finding suitable tin coatings in lithium batteries and for the replacement of tin-lead coatings in printed circuit boards and solder contacts in electronics. There has been growing search for new anode materials for rechargeable lithium batteries. Carbonaceous materials are widely used and various types of oxide and nitride materials have also been explored. ${ }^{72}$ Many investigations have discussed the irreversible capacity of tin electrodes in lithium batteries. Some have provided suggestions to avoid such anomalous high voltage irreversible capacity, for example by rapid discharging the cell to 0.8 $\mathrm{V}$ then limiting the recharging voltage to $1.5 \mathrm{~V}$ or using tin alloying elements. ${ }^{73}$ Another 
example is the electrodeposition of tin from a room temperature molten salt, e.g. 1-methyl-3ethylimidazolium chloride. ${ }^{74}$

Tin has been deposited onto carbon paper as an anode for lithium ion batteries. Unlike tin deposited onto copper foil, tin on carbon papers can undergo higher cycling stability during lithium insertion-withdrawal cycles) at high current density. The carbon paper has a porous, three-dimensional matrix with interconnected, micron-sized carbon fibres. The structure has allowed the volume changes during cycling and helped to reduce deposit pulverization and maintained electrical contact after many cycles. ${ }^{75}$ It was reported that, during charging and discharging in lithium batteries, large volume changes were observed during expansion and contraction. This caused the deposits to fracture and pulverized the electrode thus resulting in significant loss in capacity. The effect of roughened copper foil has also been demonstrated to improve the cycle life of a tin anode in a lithium battery. ${ }^{76} \mathrm{In}$-situ atomic force microscopy was used to study the origin of large irreversible capacity in using tin as anode material in lithium batteries. The AFM images were recorded continuously during cyclic voltammetry and charge-discharge experiments. It was reported that the tin and lithium formed alloys and dealloyed most significantly in the first and second cycles. This surface roughening destroyed the existing surface film and provided an increased active area. ${ }^{77}$

Finally, the long-established problem of whisker formation on storage or use of tin deposits should be mentioned, following electrodeposition. This has been well studied in the literature, including a recent review by research workers at Loughborough University. ${ }^{78}$ Whisker growth in tin deposits is more rapid on brass substrates compared to other materials, such as copper. As a result, studies investigating the effect of process variables on tin whisker formation are often conducted on brass substrates to take advantage of the enhanced whisker growth rates. A 
detailed analysis of zinc/zinc oxide distribution at the surface of the tin deposit has been carried out. Using a commercial bright tin electroplating bath, the formation of zinc oxide at the surface of tin deposits on brass has been investigated. Analyses showed the presence of zinc oxide on the surface of the tin deposit within 1 day after electroplating. During storage at room temperature, a network of zinc oxide formed at the surface grain boundaries, the extent increasing with time. Hence zinc surface diffusion can play a critical role in whisker growth for tin deposits on brass.

Tin whiskering remains a reliability concern in electroplated coatings used in electronic applications; despite extensive research on growth rates and mitigation strategies, no predictive theory is in place. Literature data are available for $\mathrm{Cu}$-Sn-based films and coatings as well as for board-level and flip-chip solder bumps but data are scarce for scaled-down solder volumes and for higher intermetallic-to-solder ratios. Recent studies ${ }^{79}$ have investigated whiskers in "isolated geometries" for 3-D solder-capped $\mathrm{Cu}$ microbumps having $>2$ orders of magnitude smaller solder volumes compared to state-of-the-art. To the best of the authors' knowledge, this is the first time $\mathrm{Sn}$ whisker growth is reported in isolated solder volumes (e.g. $<8 \mu \mathrm{m}$ side cube). Whiskers propensity was evaluated using JEDEC industrial specifications. The evaluated structures were: $3.5 \mu \mathrm{m}$-thick $\mathrm{Cu}$-Sn films and $15 \mu \mathrm{m}$-diameter electroplated solder capping ( $\mathrm{Sn}, \mathrm{SnAg}, \mathrm{SnCu}$ ) on $\mathrm{Cu}$ microbumps (as-plated vs. reflowed). Selected Sn whiskers and "whisker-like" features were analysed and identified experimentally with SEM, EDX and FIB. In the absence of a predictive model, first-order and "what if" calculations based on IMC molar volume and oxide cracking hypotheses were carried out. This approach provides figures of merit for Sn whisker propensity with (1) different bump-limiting metallization (BLM) cases e.g. $\mathrm{Cu}, \mathrm{Ni}, \mathrm{Co}$ and (2) further microbump scaling. Future research recommendations are outlined to mitigate manufacturing risks by controlling the "sit time" between bumping and 
stacking. The electrodeposition of tin coatings from deep eutectic solvents and their subsequent whisker growth has been considered at length in a $2014 \mathrm{PhD}$ thesis at Loughborough University 80.

\section{Conclusions}

1. Electrodeposition of tin and tin-copper alloys is important to many industries. For example, bright tin coatings can be aesthetically pleasing (e.g., for jewellery and decorative applications); tin-copper alloys can provide solder materials (e.g. in microelectronics and printed circuit boards).

2. Many investigations have shown that tin and tin-copper coatings can be found in engine bearings (for their enhanced wear and corrosion properties), tinplate in food packaging (e.g. protection to steel), as anodes materials in lithium batteries, bronzes in musical instruments and as coatings in culinary equipment.

3. Recent studies of tin and tin-copper alloy electrodeposition have been carried out from acidic baths, mainly from sulphuric acid and methanesulfonic acid. In acidic electrolytes, tin is usually electrodeposited with little activation overpotential

4. The formulations of acidic baths are usually complex since they normally contain a variety of additives and complexants for bath stability and to enhance deposit quality. In the absence of additives tin deposits may be porous and dendritic and electrodeposition of tin-copper alloys becomes more difficult due to the large difference in the reduction potential.

5. Electrodeposition of tin has classically been achieved by constant current between the cathode and anode. Recent studies have suggested the use of pulsed current and potential techniques, which can give enhanced properties such as nanostructure deposits and compositional modulated coatings. 
6. The recently introduced multi-layer and composite tin deposits can provide improved coating properties and may find applications as enhanced engine bearing materials and as anode materials in lithium batteries.

\section{Recommendations for further work}

A number of topics merit further research work on the electrodeposition of tin:

1. Deposition of a wider range of surface finish from MSA solutions due to their environmental benefits, moderate costs and relative ease of maintenance.

2. Time-evolution of deposit nucleation and growth morphology, including whisker growth of aged deposits on various substrates, with different pre-treatments, and with different posttreatments, on storage and prolonged use.

3. In-situ infra-red and Raman spectroscopy studies of single and multiple bath additives on electrode surfaces to establish mechanisms of their interaction during nucleation and growth of tin deposits.

4. Further studies of additives in MSA tin baths and their interactive effects, particularly for aged solutions.

5. Examination of a wider range of bath and electroplating variables in pulsed plating of tin from MSA baths.

6. While long-term whisker formation is considered to be rare in tin deposits from methanesulfonic acid, even on brass substrates, careful, long-term studies of $\mathrm{Sn}-\mathrm{Cu}$ alloy deposits from coating system are required.

\section{Acknowledgements}


Parts of this review have been informed by the earlier doctoral studies programme of CTJL at the University of Southampton. The authors gratefully acknowledge funding by the Research Institute for Industry at Southampton University. 


\section{List of symbols}

c concentration of stannous ions

$\mathrm{mol} \mathrm{cm}{ }^{-3}$

$D \quad$ diffusion coefficient of $\mathrm{Sn}^{2+}$ ions

$\mathrm{cm}^{2} \mathrm{~s}^{-1}$

E electrode potential

V

j $\quad$ current density

$\mathrm{A} \mathrm{cm}^{-2}$

$j_{c t} \quad$ pure charge transfer current density for tin deposition

A

$j_{L} \quad$ limiting current density for tin deposition

$\mathrm{A} \mathrm{cm}^{-2}$

$j_{p} \quad$ peak current density

$\mathrm{A} \mathrm{cm}^{-2}$

$q \quad$ electrical charge under the current $v s$. potential curve

$\mathrm{C}$

$v \quad$ linear potential sweep rate

$\mathrm{V} \mathrm{s}^{-1}$

$z \quad$ number of electrons involved in the electrode process

dimensionless

Greek

$v \quad$ kinematic viscosity of the electrolyte

$\mathrm{cm}^{2} \mathrm{~s}^{-1}$

$\omega \quad$ electrode rotation speed

$\operatorname{rad~s}^{-1}$

\section{Abbreviations}

ENSA ethoxylated $\alpha$-naphthol sulfonic acid

MSA methanesulfonic acid

PEG polyethylene glycol

PPG polypropylene glycol

POELE polyoxyethylene lauryl ether

RCE rotating cylinder electrode

$\mathrm{RCH} \quad$ rotating cylinder Hull

RDE rotating disc electrode 


\section{References}

1. www.http://enthone.com/Industries/Electronics_Solutions.aspx; accessed 12 November 2015.

2. A. Brenner, Electrodeposition of copper-tin alloys, in Electrodeposition of Alloys, Academic Press, London, 1963; p. 497.

3. M. Jordan, The Electrodeposition of Tin and its Alloys, E.G. Leuze, Saulgau, Germany, 1995.

4. D.R. Gabe, Principles of Metal Surface Treatment and Protection, $2^{\text {nd }}$ edn., Elsevier, London, 1978.

5. M.D. Gernon, M. Wu, T. Buszta, P. Janney, Green Chemistry, 1999, 1, 127.

6. A.P. Abbott, G. Capper, K.J. McKenzie, K.S. Ryder, Electrodeposition of zinc-tin alloys from deep eutectic solvents based on choline chloride, J. Electroanal. Chem., 2007, 599, $288-294$.

7. Y. Nakamura, N. Kaneko, H. Nezu, J. Appl. Electrochem., 1994, 24, 569.

8. Y. Nakamura, N. Kaneko, H. Nezu, J. Appl. Electrochem., 1994, 24, 404.

9. I.S. Zavarine, O. Khaselev, Y. Zhang, J. Electrochem. Soc., 2003, 150, C202.

10. A. Aragon, M.G. Figueroa, R.E. Gana, J. Appl. Electrochem., 1992, 22, 558.

11. J. Lee, J. Kim, B. Chang, H.T. Kim, S. Park, J. Electrochem. Soc., 2004, 151, C333.

12. G.S. Tzeng, Plat. Surf. Finish., 1995, 67, 130.

13. G.S. Tzeng, S.H. Lin, Y.Y. Wang, C.C. Wan, J. Appl. Electrochem., 1996, 26, 419.

14. G.I. Medvedev, N.A. Makrushin, Russ. J. Appl. Chem., 2002, 75, 1324.

15. S. Wen, J.A. Szpunar, Electrochim. Acta, 2005, 50, 2393.

16. F.J. Barry, V.J. Cunnane, J. Electroanal. Chem., 2002, 537, 151.

17. C. Ponce de Leon, F.C. Walsh, Versatile electrochemical coatings and surface layers from methanesulfonic acid, Surf. Coat. Techn., (2014), 259, 676-697.

18. C.T.J. Low, C. Kerr, C. Ponce-de-León, F.C. Walsh, Electrodeposition of tin at static and rotating copper disk electrodes: voltammetry, nucleation and morphology, Ch. 13 in U.S.

Mohanty, (Ed), Electrodeposition: Properties, Processes and Applications, Nova publishers, New York, 2012, pp 283-296.

19. Y. Yau, J. Electrochem. Soc., 2000, 147, 1071.

20. R.A.T. de Greef and L.J.J. Janssen, J. Appl. Electrochem., 2001, 31, 693.

21. I. Petersson, E. Ahlberg, J. Electroanal. Chem., 2000, 485, 166.

22. D. Pletcher, A First Course in Electrode Processes, 2nd edn., Royal Society of Chemistry, 2009. 
23. F.C. Walsh, A First Course in Electrochemical Engineering, The Electrochemical Consultancy, Romsey, 1993.

24. A.J. Bard, L.R. Faulkner, Electrochemical Methods: Fundamentals and Application, $2^{\text {nd }}$ Edition, John Wiley \& Sons, New York, 2001.

25. C.L. Rinne, J.J. Hren, P.S. Fedkiw, J. Electrochem. Soc., 2002, 149, C150.

26. J. Chunxin, G. Oskam, P.C. Searson, Surf. Sci., 2001, 492, 115.

27. L. Heerman, A. Tarallo, J. Electroanal. Chem., 1999, 470, 70.

28. A.N. Correia, S.A.S. Machado, L.A. Avaca, J. Electroanal. Chem., 2000, 488, 110.

29. M. Palomar-Pardavé, B.R. Scharifker, E.M. Arce, M. Romero-Romo, Electrochim. Acta, $2005,50,4736$.

30. M.E. Hyde, R.G. Compton, J. Electroanal. Chem., 2003, 549, 1.

31. D. Grujicie, B. Pesic, Electrochim. Acta, 2004, 49, 4719.

32. D. Grujicie, B. Pesic, Electrochim. Acta, 2005, 50, 4426.

33. B.R. Scharifker, G.J. Hills, Electrochim. Acta, 1983, 28, 879.

34. G. Oskam, P.M. Vereecken, P.C. Searson, J. Electrochem. Soc., 1999, 146, 1436.

35. G.A. Gunawardena, G.J. Hills, I. Montenegro, B.R. Schariker, J. Electroanal. Chem., 1982, 138, 225.

36. M.P. Pardave, M.T. Ramirez, I. Gonzales, A. Serruya, B.R. Scharifker, J. Electrochem. Soc., 1996, 143, 1551.

37. C.T.J. Low, C. Kerr, B.D. Barker, J.R. Smith, S.A. Campbell, F.C. Walsh, Trans. Inst. Metal Finish., 2008, 86, 148.

38. C.T.J. Low, F.C. Walsh, Electrochim. Acta, 2008, 53, 5280.

39. C.T.J. Low, F.C. Walsh, J. Electroanal. Chem., 2008, 615, 91.

40. M.D. Gernon, H.S. Elroi, B.A. DeCesare, F.P. Butler, US 5296128, 011993, Technic Inc, 1993.

41. J.C. Bazan, J.M. Bisang, J. Appl. Electrochem., 2004, 34, 501.

42. G.I. Medvedev, N.A. Makrushin, Russ. J. Appl. Chem., 2004, 77, 1781.

43. A. Aragon, M.G. Figueroa, R.E. Gana, J.H. Zagal, J. Appl. Electrochem., 1992, 22, 558

44. Y. Nakamura, N. Kaneko, H. Nezu, J. Appl. Electrochem., 1994, 24, 569.

45. Y. Nakamura, N. Kaneko, M. Nakamura, H. Nezu, J. Appl. Electrochem., 1994, 24, 404.

46. N. Kaneko, N. Shinohara, H. Nezu, Electrochim. Acta, 1992, 37, 2403.

47. M. Clarke, J.A. Bernie, Electrochim. Acta, 1967, 12, 205.

48. G.I. Medvedev, N.A. Makrushin, Russ. J. Appl. Chem., 2001, 74, 1842.

49. M. Fukufa, K. Imayoshi, Y. Matsumoto, Surf. Coat. Tech., 2003, 169, 128. 
50. F. Xiao, X. Shen, F.Z. Ren, A.A. Volinsky, Int. J. Minerals, Metallurgy, and Materials, 2013, 20, 472.

51. N.M. Martyak, R. Seefeldt, Trans. Inst. Met. Finish, 2003, 78, 81.

52. N.M. Martyak, R. Seefeldt, Trans. Inst. Met. Finish, 2005, 83, 43.

53. C.L. Rinne, J.J. Hren, P.S. Fedkiw, J. Electrochem. Soc., 2002, 149, C150.

54. Y. Yau, J. Electrochem. Soc., 2000, 147, 1071.

55. P.A. Kohl, J. Electrochem. Soc., 1982, 129, 1196.

56. M.A. Ashworth, G.D. Wilcox, R.L. Higginson, R.J. Heath, C. Liu, R.J. Mortimer, Microelectron. Reliab., 2015, 55, 180.

57. M. Sobiech, J. Teufel, U. Welzel, E.J. Mittemeijer, W. Hügel, J. Electron. Mater., 2011, 40(11), 2300.

58. L. Sauter, A. Seekamp, Y. Shibata, Y. Kanameda, H. Yamashita, Microelectron. Reliab., 2010, 50(9-11), 1631.

59. A. Baated, K.S. Kim, K. Suganuma, J. Mater. Sci.: Mater. Electron., 2011, 22, 1685.

60. T. Teshigawara, T. Nakata, K. Inoue, T. Watanabe, Scripta Mater., 2001, 44, 2285.

61. E. Gómez, E. Guaus, F. Sanz, E. Vallés, J. Electroanal. Chem., 1999, 46, 5163.

62. C.J.V. Velzen, M. Sluyters-Rehbach, J.H. Sluyters, Electrochim. Acta, 1995, 40, 1469.

63. J. Torrent-Burguès, E. Guaus, F. Sanz, J. Appl. Electrochem., 2002, 32, 225.

64. M.M. Hukovic, S. Omanovic, A. Jukic, Electrochim. Acta, 1999, 45, 977.

65. S.H. Bonilla, J. Rodriquez, C.F. Zinola, C. Bello, B.F. Giannetti, Corr. Sci., 2005, 47, 835 .

66. C.A. Gervasi, P.E. Alvarez, Corr. Sci., 2005, 47, 69.

67. I. Vitina, V. Rubene, M. Pelēcis, I. Zālìte, O. Kovalova, Thin Solid Films, 1998, 323, 23.

68. Z. Peng, Z. Shi, M. Liu, Chem. Commun., 2000, 2125.

69. R.A.T. de Greef, L.J.J. Jansen, J. Appl. Electrochem., 2001, 31, 693.

70. B.X, Huang, P. Tornatore, Y. Li, Electrochim. Acta, 2000, 46, 671.

71. A.J. Chaudhary, S.O.V. Dando, S.M. Grimes, J. Chem. Techn. Biotech, 2001, 76, 47.

72. S. Machill, T. Shodai, Y. Sakurai, J. Yamaki, J. Power Sources, 1998, 73, 216.

73. S.D. Beattie, T. Hatchard, A. Bonakdarpour, K.C. Hewitt, J.R. Dahn, J. Electrochem. Soc., 2003, 150, A701.

74. Y.S. Fung, D.R. Zhu, J. Electrochem. Soc., 2002, 149, A319.

75. C. Arbizzani, S. Beninati, M. Lazzari, M. Mastragostino, J. Power Sources, 2005, 141, 149.

76. H. Morimoto, S. Tobishima, H. Negishi, J. Power Sources, 2005, 146, 469. 
77. M. Inaba, T. Uno, A. Tasaka, J. Power Sources, 2005, 146, 473.

78. M.A. Ashworth, G.D, Wilcox, R.L. Higginson, R.J. Heath, C. Liu, Trans. Inst. Met. Finish, 2013, 91, 261.

79. G.P. Vakanas, B. Vandecasteele, D. Schaubroek, J. De Messemaeker, G. Willems, M.A. Ashworth, G.D. Wilcox, I. De Wolf, Microelectronics Reliability, 2014, 55, 180.

80. C. Stuttle, The electrodeposition of tin coatings from deep eutectic solvents and their subsequent whisker growth, PhD thesis, 2014, Loughborough University. 


\begin{tabular}{|c|c|}
\hline Industrial sector & $\begin{array}{c}\text { Initiatives and } \\
\text { modern developments }\end{array}$ \\
\hline Microele & $\begin{array}{l}\text { - Lead-free compliance. } \\
\text { - Miniaturization of wafer bumping. } \\
\text { - Improved whisker-free deposits. } \\
\text { - Enhanced flip-chip bonding. }\end{array}$ \\
\hline 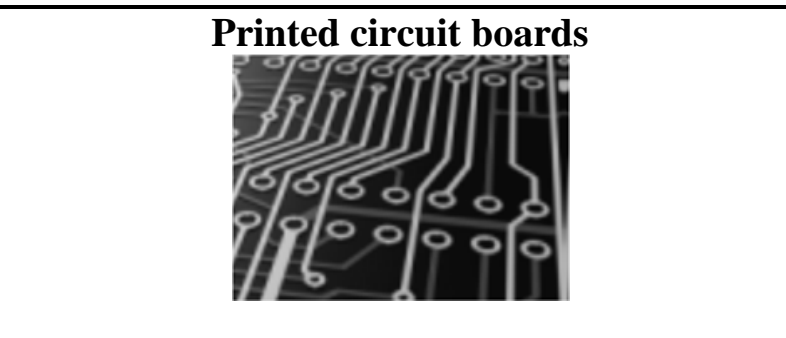 & $\begin{array}{l}\text { - Lead free directives. } \\
\text { - Miniaturization of high aspect ratio } \\
\text { microvias. } \\
\text { - High throwing power deposition. } \\
\text { - Nanoscale semiconductor wafers and } \\
\text { lead outs. } \\
\text { - Possible replacement for Ni-Au coating. }\end{array}$ \\
\hline Automotive a & $\begin{array}{l}\text { - Improved corrosion resistance and } \\
\text { tribology. } \\
\text { - Meeting new regulations for hazardous } \\
\text { plating. } \\
\text { - Partial replacements for } \mathrm{Pb} \text {-, hexavalent } \\
\text { Cr- and Cd-free coatings. } \\
\text { - Improved coating properties. }\end{array}$ \\
\hline Jewellery a & $\begin{array}{l}\text { - Allergy-free coatings. } \\
\text { - Build-up of metallised layers on } \\
\text { plastics. } \\
\text { - Reduced cost. } \\
\text { - Substitute coatings for nickel. }\end{array}$ \\
\hline Batteries for electrochemical energy storage & $\begin{array}{l}\text { - Anodes for rechargeable Li-ion battery. } \\
\text { - Improving battery cycle life } \\
\text { - Theoretical capacity: } 992 \mathrm{~mA} \mathrm{~h} \mathrm{~g}^{-1} \mathrm{Sn} \text {. }\end{array}$ \\
\hline
\end{tabular}

Table 1. Applications of tin and tin-copper alloy electrodeposition. Images courtesy of Enthone Inc. ${ }^{1}$ 


\begin{tabular}{|c|c|c|c|}
\hline Tin salt used in bath & Electrolyte & Additives & Ref. \\
\hline $0.25 \mathrm{~mol} \mathrm{dm}^{-3} \mathrm{SnSO}_{4}$ & $\begin{array}{c}10 \% \text { vol. } \mathrm{C}_{2} \mathrm{H}_{5} \mathrm{OH} \\
0.5 \mathrm{~mol} \mathrm{dm}^{-3} \mathrm{H}_{2} \mathrm{SO}_{4} \\
\end{array}$ & $\begin{array}{c}\mathrm{C}_{6} \mathrm{H}_{5}-\mathrm{CH}=\mathrm{CHCOCH}_{3} \\
\mathrm{C}_{18} \mathrm{H}_{37} \mathrm{~N}\left[\left(\mathrm{CH}_{2} \mathrm{CH}_{2} \mathrm{O}\right)_{4} \mathrm{H}_{2}\right.\end{array}$ & 7 \\
\hline $\begin{array}{c}0.005 \text { to } 0.25 \\
\mathrm{~mol} \mathrm{dm}^{-3} \mathrm{SnSO}_{4}\end{array}$ & $\begin{array}{c}10 \% \text { vol. } \mathrm{C}_{2} \mathrm{H}_{5} \mathrm{OH} \\
0.5 \mathrm{~mol} \mathrm{dm}^{-3} \mathrm{H}_{2} \mathrm{SO}_{4}\end{array}$ & $\begin{array}{c}\mathrm{C}_{6} \mathrm{H}_{5}-\mathrm{CO}=\mathrm{C}_{6} \mathrm{H}_{5} \\
\mathrm{C}_{6} \mathrm{H}_{5}-\mathrm{CH}=\mathrm{CHCOCH}_{3} \\
\mathrm{C}_{18} \mathrm{H}_{37} \mathrm{~N}\left[\mathrm{CH}_{2} \mathrm{CH}_{2} \mathrm{OH}\right]_{2} \\
\mathrm{C}_{18} \mathrm{H}_{37} \mathrm{~N}\left[\left(\mathrm{CH}_{2} \mathrm{CH}_{2} \mathrm{O}\right)_{4} \mathrm{H}\right]_{2} \\
\mathrm{C}_{18} \mathrm{H}_{37} \mathrm{~N}- \\
\left.\left[\left(\mathrm{CH}_{2} \mathrm{CH}_{2} \mathrm{O}\right)_{10} \mathrm{H}\right]_{2}\right)\end{array}$ & 8 \\
\hline $0.5 \mathrm{~mol} \mathrm{dm}^{-3} \mathrm{SnCH}_{3} \mathrm{SO}_{3}$ & $1.0 \mathrm{~mol} \mathrm{dm}^{-3} \mathrm{CH}_{3} \mathrm{SO}_{3} \mathrm{H}$ & $\begin{array}{c}\text { Igepal CA520, DM970 } \\
\text { Triton X-100, } \\
\text { phenolphthalein, } \\
\text { PEG, PPG }\end{array}$ & 9 \\
\hline $25 \mathrm{~g} \mathrm{dm}^{-3} \mathrm{Sn}^{2+}$ & $60 \mathrm{~g} \mathrm{dm}^{-3} \mathrm{H}_{2} \mathrm{SO}_{4}$ & Triton X-102 & 10 \\
\hline $0.14 \mathrm{~mol} \mathrm{dm}^{-3} \mathrm{SnSO}_{4}$ & $\begin{array}{l}0.033 \mathrm{~mol} \mathrm{dm}^{-3} \\
\mathrm{HOC}_{6} \mathrm{H}_{4} \mathrm{SO}_{3} \mathrm{H}\end{array}$ & $\begin{array}{l}\text { Ethoxylated } \alpha \text {-naphthol } \\
\text { sulfonic acid (ENSA) }\end{array}$ & 11 \\
\hline $0.01 \mathrm{~mol} \mathrm{dm}^{-3} \mathrm{SnSO}_{4}$ & $10 \%$ vol. $\mathrm{H}_{2} \mathrm{SO}_{4}$ & $\begin{array}{l}\text { Benzaldehyde, } \\
\text { acetophenone, } \\
\text { 4-methyl 2-pentone }\end{array}$ & 12 \\
\hline $0.01 \mathrm{~mol} \mathrm{dm}^{-3} \mathrm{SnSO}_{4}$ & $10 \%$ vol. $\mathrm{H}_{2} \mathrm{SO}_{4}$ & $\begin{array}{c}\text { Formaldehyde, } \\
\text { benzaldehyde } \\
\text { propionaldehyde }\end{array}$ & 13 \\
\hline $30 \mathrm{~g} \mathrm{dm}^{-3} \mathrm{SnSO}_{4}$ & $100 \mathrm{~g} \mathrm{dm}^{-3} \mathrm{H}_{2} \mathrm{SO}_{4}$ & $\begin{array}{c}\text { Synthanol 2, formalin, } \\
\text { benzyl alcohol }\end{array}$ & 14 \\
\hline $0.2 \mathrm{~mol} \mathrm{dm}^{-3} \mathrm{SnSO}_{4}$ & $0.3 \mathrm{~mol} \mathrm{dm}^{-3} \mathrm{H}_{2} \mathrm{SO}_{4}$ & Gelatin & 15 \\
\hline $0.14 \mathrm{~mol} \mathrm{dm}^{-3} \mathrm{SnSO}_{4}$ & $2.0 \mathrm{~mol} \mathrm{dm}^{-3} \mathrm{H}_{2} \mathrm{SO}_{4}$ & $\begin{array}{c}\text { Triton X-100, } \\
\text { formaldehyde, } \\
\text { phenyl-2-butenalimine }\end{array}$ & 16 \\
\hline
\end{tabular}

Table 2. Examples of tin electrodeposition from acidic baths. 


\begin{tabular}{|c|c|c|}
\hline Additives & Main role of additives & Ref. \\
\hline $\begin{array}{c}\mathrm{C}_{6} \mathrm{H}_{5}-\mathrm{CH}=\mathrm{CHCOCH}_{3} \\
\mathrm{C}_{18} \mathrm{H}_{37} \mathrm{~N}\left[\left(\mathrm{CH}_{2} \mathrm{CH}_{2} \mathrm{O}\right)_{4} \mathrm{H}\right]_{2}\end{array}$ & $\begin{array}{l}\text { Inhibits stannous ions } \\
\text { reduction and reduces grain } \\
\text { size and roughness. }\end{array}$ & 7 \\
\hline $\begin{array}{c}\mathrm{C}_{6} \mathrm{H}_{5}-\mathrm{CO}=\mathrm{C}_{6} \mathrm{H}_{5} \\
\mathrm{C}_{6} \mathrm{H}_{5}-\mathrm{CH}=\mathrm{CHCOCH}_{3} \\
\mathrm{C}_{18} \mathrm{H}_{37} \mathrm{~N}\left[\mathrm{CH}_{2} \mathrm{CH}_{2} \mathrm{OH}\right]_{2} \\
\mathrm{C}_{18} \mathrm{H}_{37} \mathrm{~N}\left[\left(\mathrm{CH}_{2} \mathrm{CH}_{2} \mathrm{O}\right)_{4} \mathrm{H}\right]_{2} \\
\left.\mathrm{C}_{18} \mathrm{H}_{37} \mathrm{~N}-\left[\left(\mathrm{CH}_{2} \mathrm{CH}_{2} \mathrm{O}\right)_{10} \mathrm{H}\right]_{2}\right)\end{array}$ & $\begin{array}{l}\text { Inhibits the reduction of } \\
\text { stannous ions with } \\
\text { increasing additives } \\
\text { concentration. A } \\
\text { combination of additives } \\
\text { induces levelling and grain } \\
\text { refining effects for uniform, } \\
\text { smooth deposits. }\end{array}$ & 8 \\
\hline $\begin{array}{c}\text { Igepal CA520, DM970 } \\
\text { Triton X-100 } \\
\text { Polyethylene glycol (PEG) } \\
\text { Polypropylene glycol (PPG) } \\
\text { Phenolphthalein }\end{array}$ & $\begin{array}{l}\text { Deposition potential } \\
\text { affected. Adsorption of } \\
\text { additives onto the electrode } \\
\text { surface occurred. A } \\
\text { combination of additives } \\
\text { facilitated adsorption, } \\
\text { modified grain size and } \\
\text { structure for smooth, bright } \\
\text { deposits. }\end{array}$ & 9 \\
\hline Triton X-102 & $\begin{array}{l}\text { At stationary electrodes, a } \\
\text { limiting current density was } \\
\text { observed at the critical } \\
\text { micelle concentration. }\end{array}$ & 10 \\
\hline Ethoxylated $\alpha$-naphthol sulfonic acid (ENSA) & $\begin{array}{l}\text { Affected mass transport and } \\
\text { additive adsorption changed } \\
\text { the tin overpotential. }\end{array}$ & 11 \\
\hline $\begin{array}{c}\text { Benzaldehyde } \\
\text { Acetophenone } \\
\text { 4-methyl 2-pentone }\end{array}$ & $\begin{array}{l}\text { Limiting current density and } \\
\text { diffusion coefficient } \\
\text { decreased from } \\
\text { hydrophobic to hydrophilic } \\
\text { additives. }\end{array}$ & 12 \\
\hline $\begin{array}{l}\text { Formaldehyde } \\
\text { Propionaldehyde } \\
\text { Benzaldehyde }\end{array}$ & $\begin{array}{l}\text { Aldehyde type were } \\
\text { reduced to alcohols, which } \\
\text { adsorbed and hindered the } \\
\text { charge transfer. }\end{array}$ & 13 \\
\hline $\begin{array}{c}\text { Syntanol }^{2} \\
\text { Formaldehyde } \\
\text { Benzyl alcohol }\end{array}$ & $\begin{array}{l}\text { Deposition potential } \\
\text { affected additive adsorption } \\
\text { and desorption, to give dull } \\
\text { and reflective surfaces. }\end{array}$ & 14 \\
\hline Gelatin & $\begin{array}{l}\text { Improved surface coverage; } \\
\mathrm{H}_{2} \text { was evolved at a more } \\
\text { negative potential. }\end{array}$ & 15 \\
\hline $\begin{array}{c}\text { Triton X-100 } \\
\text { Phenyl-2-butenalimine } \\
\text { Formaldehyde }\end{array}$ & $\begin{array}{l}\text { Peak potential shifted with } \\
\text { additive concentration; } \\
\text { additives adsorption altered } \\
\text { charge transfer and could be } \\
\text { time dependent. }\end{array}$ & 16 \\
\hline
\end{tabular}

Table 3. The role of electrolyte additives on tin deposition from acidic baths. 


\begin{tabular}{|c|c|c|}
\hline Antioxidant $^{+}$ & Reaction with oxygen & $\begin{array}{c}\text { Theoretical } \\
\text { antioxidant } \\
\text { consumption } \\
\text { ratio }\end{array}$ \\
\hline Sodium sulphite $(s)$ & $2 \mathrm{Na}_{2} \mathrm{SO}_{3}+\mathrm{O}_{2}=2 \mathrm{Na}_{2} \mathrm{SO}_{4}$ & 7.9 \\
\hline Hydrazine $(l)$ & $\mathrm{N}_{2} \mathrm{H}_{4}+\mathrm{O}_{2}=2 \mathrm{H}_{2} \mathrm{O}+\mathrm{N}_{2}$ & 1.0 \\
\hline Carbohydrazide $(l)$ & $\mathrm{H}_{6} \mathrm{~N}_{4} \mathrm{CO}+2 \mathrm{O}_{2}=\mathrm{CO}_{2}+2 \mathrm{~N}_{2}+3 \mathrm{H}_{2} \mathrm{O}$ & 1.4 \\
\hline Methylethylketoxime $(l)$ & $\begin{array}{c}\left.2 \mathrm{H} 4 \mathrm{C}=\mathrm{N}_{-} \mathrm{OH}_{2}\right) \mathrm{CH}_{2} \mathrm{CH}_{3}+\mathrm{O}_{2}= \\
2 \mathrm{H}_{3} \mathrm{C}\left(\mathrm{C}=\mathrm{O}_{2}\right) \mathrm{CH}_{3} \mathrm{CH}_{3}+\mathrm{N}_{2} \mathrm{O}+\mathrm{H}_{2} \mathrm{O}\end{array}$ & 5.4 \\
\hline Hydroquinone $(s)$ & $2 \mathrm{C}_{6} \mathrm{H}_{4}(\mathrm{OH})_{2}+2 \mathrm{O}_{2}=$ & 6.9 \\
$2 \mathrm{C}_{6} \mathrm{H}_{4} \mathrm{O}_{2}+2 \mathrm{H}_{2} \mathrm{O}$ & 1.2 \\
\hline Diethylhydroxylamine $(l)$ & $\begin{array}{c}4\left(\mathrm{CH} \mathrm{CH}_{2}\right)_{2} \mathrm{NOH}_{2}+9 \mathrm{O}_{2}= \\
8 \mathrm{CH} \mathrm{CHOH}_{3} \mathrm{COOH}_{2}+2 \mathrm{~N}_{2}+14 \mathrm{H}_{2} \mathrm{O}\end{array}$ \\
\hline
\end{tabular}

Table 4. Examples of antioxidants used in the removal of dissolved oxygen from acid tin baths and their complete reaction with dissolved oxygen.

* Theoretical antioxidant consumption ratio $=M_{\text {antioxidant }} / M_{\text {oxygen., }}$ where $M$ is the molar mass.

${ }^{+}(s)$ and $(l)$ denote solid and liquid. 


\section{Figure captions}

Figure 1. The voltammetry of $\mathrm{Sn}^{2+} / \mathrm{Sn}$ in an additive-free tin methanesulfonate acid electrolyte. a) The effect of potential sweep rate on the deposition and stripping of tin, b) the effect of rotating disc speed (200-4800 rev $\left.\mathrm{min}^{-1}\right)$ on the deposition of tin and c) the effect of stannous ion concentration on the deposition of tin. The electrolyte composition was $0.014 \mathrm{~mol} \mathrm{dm}^{-3} \mathrm{SnSO}_{4}$ and $12.5 \%$ vol. $\mathrm{CH}_{3} \mathrm{SO}_{3} \mathrm{H}$ at $295 \mathrm{~K}$. A static copper disc electrode of $0.28 \mathrm{~cm}^{2}$ area was used and the potential was swept at $16 \mathrm{mV} \mathrm{s}^{-1}$. After Low and Walsh. ${ }^{39}$

Figure 2. Tafel plot and half-wave potential of $\mathrm{Sn}^{2+}$ reduction to $\mathrm{Sn}$ as a function of tin concentration in the bath. a) Logarithmic plot of current density vs. electrode potential, using extrapolated pure charge transfer data. The electrolyte compositions were $0.006 \mathrm{~mol} \mathrm{dm}^{-3} \mathrm{SnSO}_{4}$ and $12.5 \%$ vol. $\mathrm{CH}_{3} \mathrm{SO}_{3} \mathrm{H}$. b) Halfwave potential $v s$. concentration of stannous ion. The copper RDE was at 200 rpm and deposition of tin was carried out in $12.5 \%$ vol. $\mathrm{CH}_{3} \mathrm{SO}_{3} \mathrm{H}$ at $295 \mathrm{~K}$. After Low and Walsh. ${ }^{39}$

Figure 3. Plots derived from Figure 1 data. a) Cathodic peak current density $v s$. the square root of potential sweep rate. b) Limiting current density vs. square root of angular velocity of the copper rotating disc electrode. c) Limiting current density vs. concentration of stannous ion. d) Inverse of current density vs. inverse square root of angular velocity of the copper RDE at $-0.459 \mathrm{~V} v s$. $\mathrm{Ag} \mid \mathrm{AgCl}$. After Low and Walsh. ${ }^{39}$

Figure 4. Plots showing the nucleation of tin onto copper in $0.014 \mathrm{~mol} \mathrm{dm}^{-3} \mathrm{SnSO}_{4}$ and $12.5 \%$ vol. $\mathrm{CH}_{3} \mathrm{SO}_{3} \mathrm{H}$ at $295 \mathrm{~K}$. a) Current transient curves showing the effect of potentiostatic deposition of tin. b) Logarithmic plot of current density vs. time at $-0.448 \mathrm{~V}$ vs. $\mathrm{Ag} \mid \mathrm{AgCl}$. c) Simulation of the current transient curve at -0.456 $\mathrm{V} v$ s. $\mathrm{Ag} \mid \mathrm{AgCl}$. d) Logarithmic plots of $j_{\max }$ and $\bigcirc t_{\max } v s$. the deposition potential. After Low and Walsh. ${ }^{39}$ 
Figure 5. Scanning electron micrographs of tin deposits from a bath containing $0.014 \mathrm{~mol}$ $\mathrm{dm}^{-3} \mathrm{SnSO}_{4}$ and $12.5 \%$ vol. $\mathrm{CH}_{3} \mathrm{SO}_{3} \mathrm{H}$ at a) $\left.\left.-0.65 \mathrm{~V}, \mathrm{~b}\right)-0.75 \mathrm{~V}, \mathrm{c}\right)-0.85 \mathrm{~V}$ and d) $-0.95 \mathrm{~V}$ vs. $\mathrm{Ag} \mid \mathrm{AgCl}$. After Low and Walsh. ${ }^{39}$

Figure 6. Changes in the deposition charge and stripping efficiency with hydroquinone addition to a methanesulphonic acid bath and storage time. a) Deposition charge. Tin was electrodeposited at $-0.5 \mathrm{~V}$ vs. $\mathrm{Ag} / \mathrm{AgCl}$ for 30 seconds. b) Stripping efficiency. Electrodeposited tin was stripped from $-0.5 \mathrm{~V}$ to $0 \mathrm{~V} v s$. $\mathrm{Ag} / \mathrm{AgCl}$ ○ $0 \mathrm{M}$ HQ, $\bigcirc 0.005 \mathrm{M} \mathrm{HQ}, \nabla 0.05 \mathrm{M} H Q$ and $\nabla 0.5 \mathrm{M}$ HQ. After Low and Walsh. ${ }^{38}$

Figure 7. Changes of the deposition charge and stripping efficiency with storage time and potential sweep rate in the absence of hydroquinone. (a) Deposition charge. Tin was electrodeposited with the potential swept from $0 \mathrm{~V}$ to $-0.65 \mathrm{~V} v s . \mathrm{Ag} / \mathrm{AgCl}$. (b) Stripping efficiency. Electrodeposited tin was stripped from $-0.65 \mathrm{~V}$ to $0 \mathrm{~V}$ vs. $\mathrm{Ag} / \mathrm{AgCl}$. fresh solution and bath aged for $\bigcirc 32$ hours, $\nabla 64$ hours, $\nabla$ 128 hours, $\square 256$ hours and $\square 512$ hours. After Low and Walsh. ${ }^{38}$

Figure 8. Effect of electrode rotation rate on tin deposition: 200, 400, 600, 800, 1200, 1600, 2400, 3200 and $4800 \mathrm{rpm}$. limiting current density. The electrolyte was freshly prepared and contained no hydroquinone. ….......... 12.5\% vol. MSA and $0.014 \mathrm{~mol} \mathrm{dm}^{-3} \mathrm{SnSO}_{4}$ and $12.5 \%$ vol. MSA at $295 \pm 2 \mathrm{~K}$. Potential sweep rate: $16 \mathrm{mV} \mathrm{s}^{-1}$. After Low and Walsh. ${ }^{38}$

Figure 9. Influence of hydroquinone to freshly prepared electrolytes. a) Voltammetry of tin deposition at various hydroquinone concentration. b) Linear dependence of the limiting current density on the square root of electrode rotation rate. $0 \mathrm{M}$ HQ, $\bigcirc 0.005 \mathrm{M} \mathrm{HQ}, \nabla 0.05 \mathrm{M}$ HQ and $\nabla 0.5 \mathrm{M}$ HQ. The base electrolyte contained $0.014 \mathrm{~mol} \mathrm{dm}^{-3} \mathrm{SnSO}_{4}$ and $12.5 \%$ vol. MSA. After Low and Walsh. 38 
Figure 10. Effect of electrode rotation rate on (a) the complete mass transport controlled region and (b) the onset of hydrogen evolution reaction. All electrolytes were $\begin{array}{llllllllllll}\text { freshly } & \text { prepared. } & - & 0 & \mathrm{M} & \mathrm{HQ}, & \bigcirc & 0.005 & \mathrm{M} & \mathrm{HQ}, & \boldsymbol{\nabla} & 0.0\end{array}$ $5 \mathrm{M} \mathrm{HQ}$ and $\nabla 0.5 \mathrm{M}$ HQ. The base electrolyte contained $0.014 \mathrm{~mol} \mathrm{dm}^{-3}$ $\mathrm{SnSO}_{4}$ and $12.5 \%$ vol. MSA. After Low and Walsh. ${ }^{38}$

Figure 11. Changes of limiting current density over storage time (a) in the absence of hydroquinone. (b) the bath contained $0.005 \mathrm{~mol} \mathrm{dm}^{-3} \mathrm{HQ}$. fresh electrolyte and those aged for $\bigcirc 32$ hours, $\nabla 64$ hours, $\nabla 128$ hours, $\square 256$ hours and $\square$ 512 hours. (c) Percentage loss in limiting current density with storage hours. $0 \mathrm{M}$ HQ, $\bigcirc 0.005 \mathrm{M}$ HQ, $\nabla 0.05 \mathrm{M}$ HQ and $\nabla 0.5 \mathrm{M}$ HQ. After Low and Walsh. ${ }^{38}$

Figure 12. The influence of a cationic fluorocarbon surfactant on tin deposition from a methanesulfonic acid bath. a) Deposition peak current density $v s$. square root of sweep rate according to the Randles-Sevčik equation. $0, \bigcirc 0.12, \nabla 0.24, \nabla$ $0.4, \square 0.8, \square 1.6$ and $\square 2.4 \%$ vol. surfactant in dimethylformamide, b) Percentage loss in the deposition peak current density with logarithmic concentration of surfactant showing the influence of sweep rate. $4 ; \bigcirc 8$; 16 ; $\nabla 32$; 64 and $\square 128 \mathrm{mV} \mathrm{s}^{-1}$ and c) Logarithm of deposition charge $v$. concentration of ForaFac ${ }^{\circledR} 1098$ in the bath $\bigcirc 0, \bigcirc 0.12, \nabla 0.24, \nabla 0.4, \mathbf{\square} 0.8$, $\square 1.6$ and $\diamond 2.4 \%$ vol. surfactant in dimethylformamide. After Low and Walsh. 39 
b)
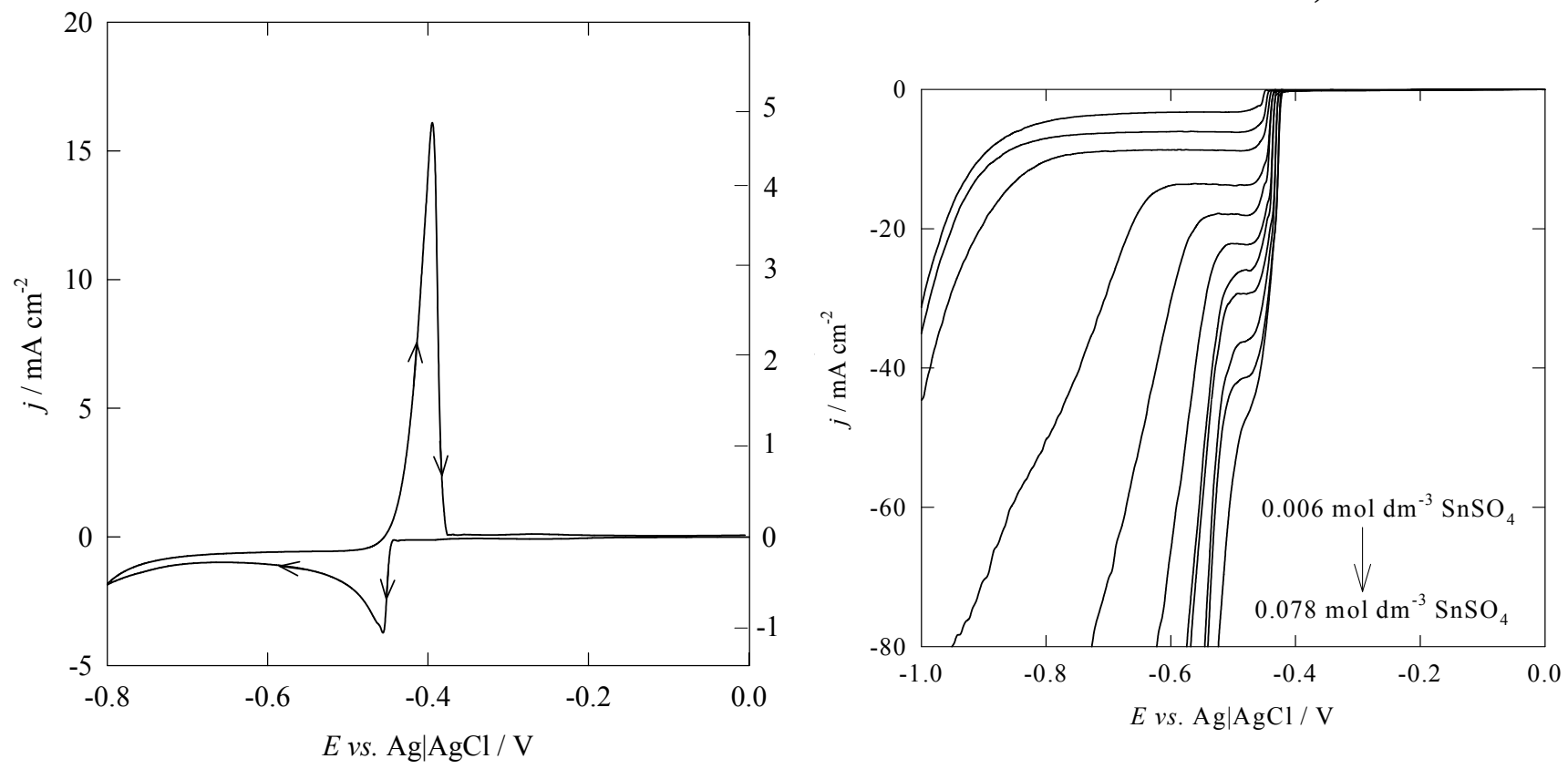

a)
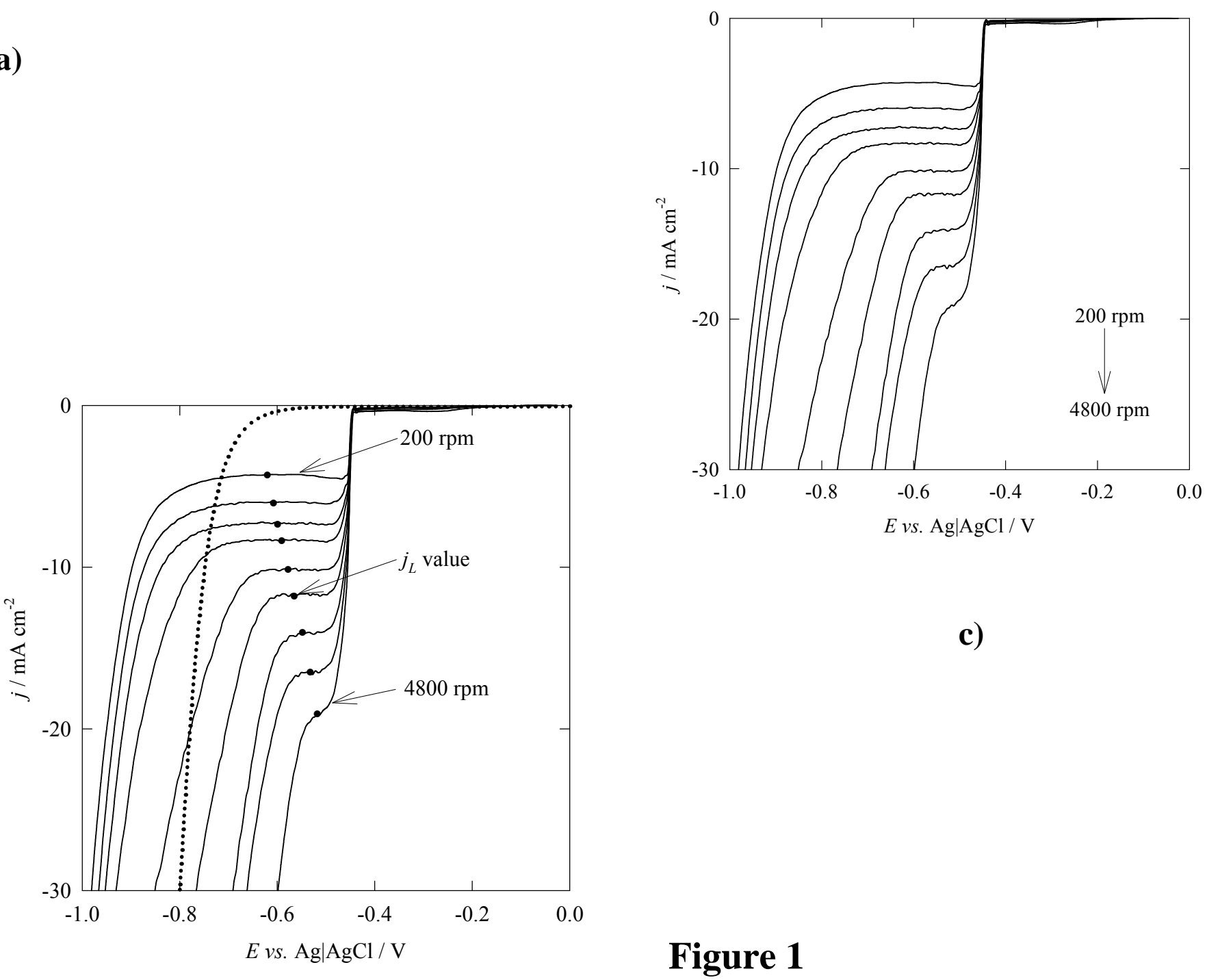

c)

Figure 1

d) 


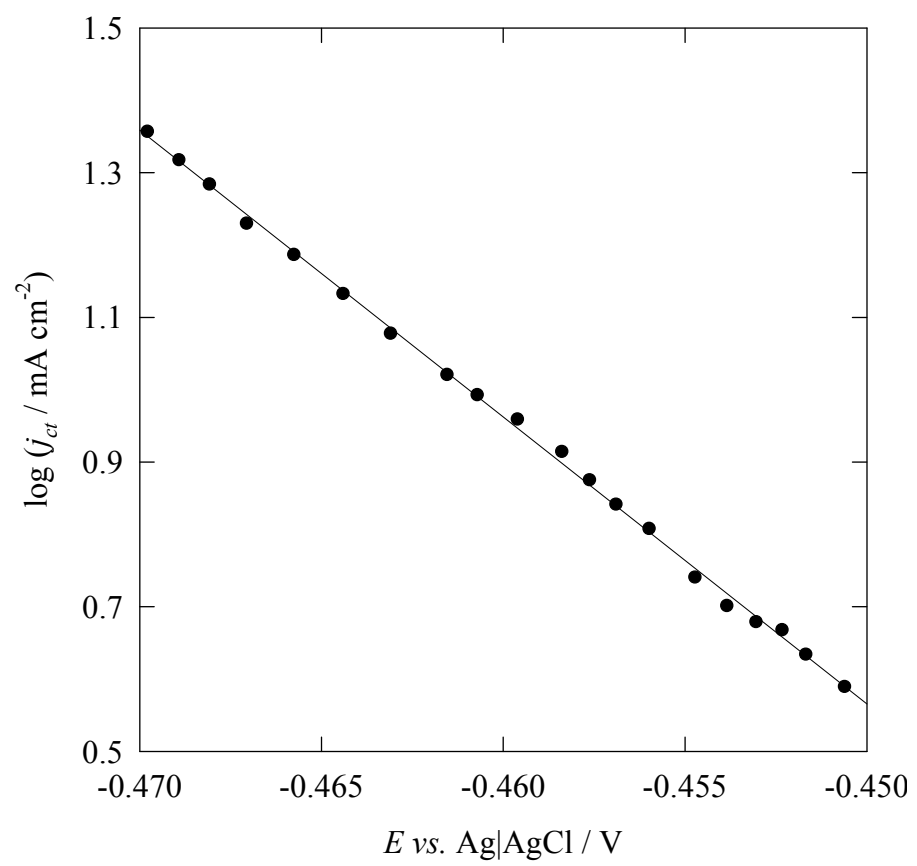

a)

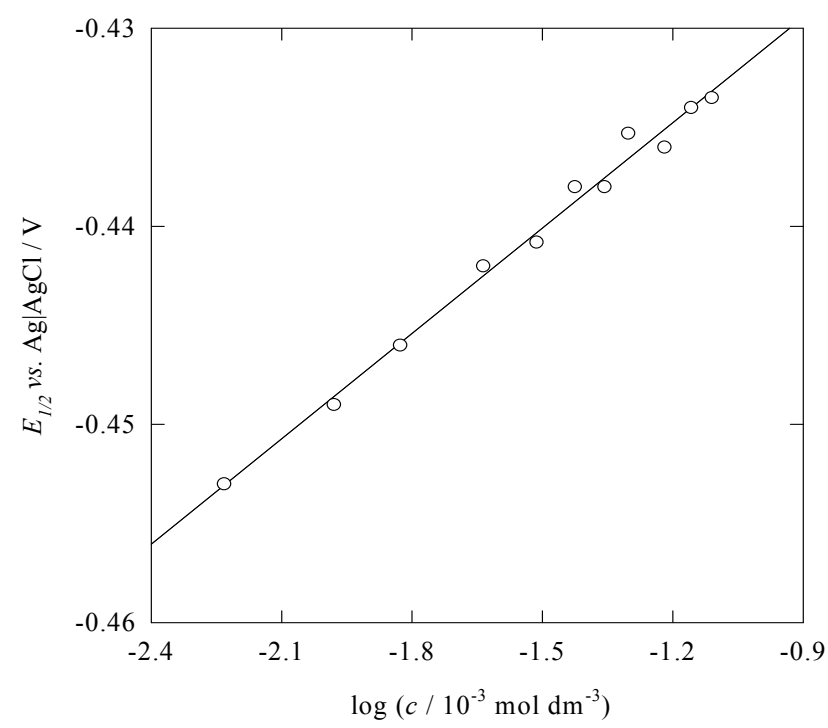

b)

Figure 2 


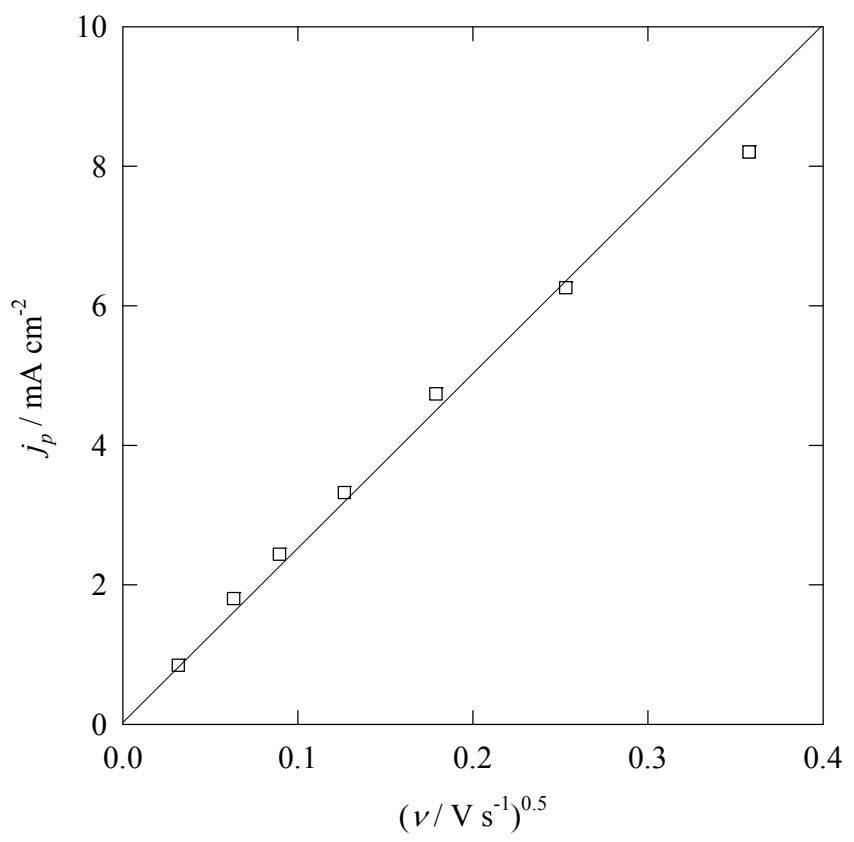

a)

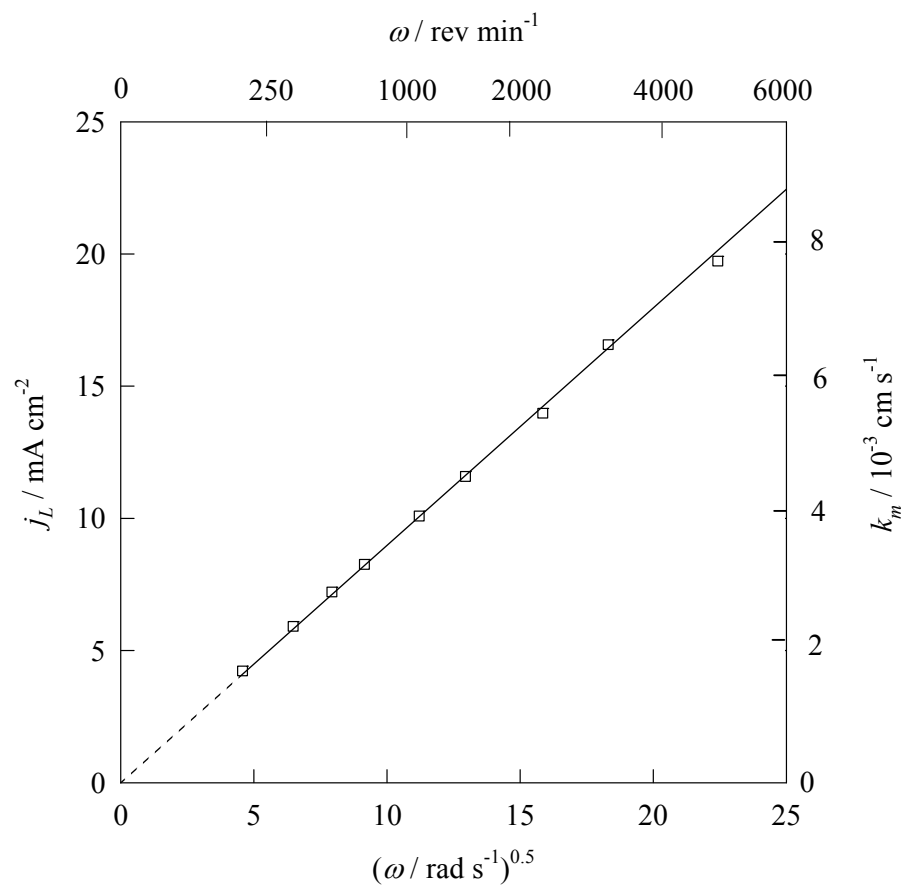

b)

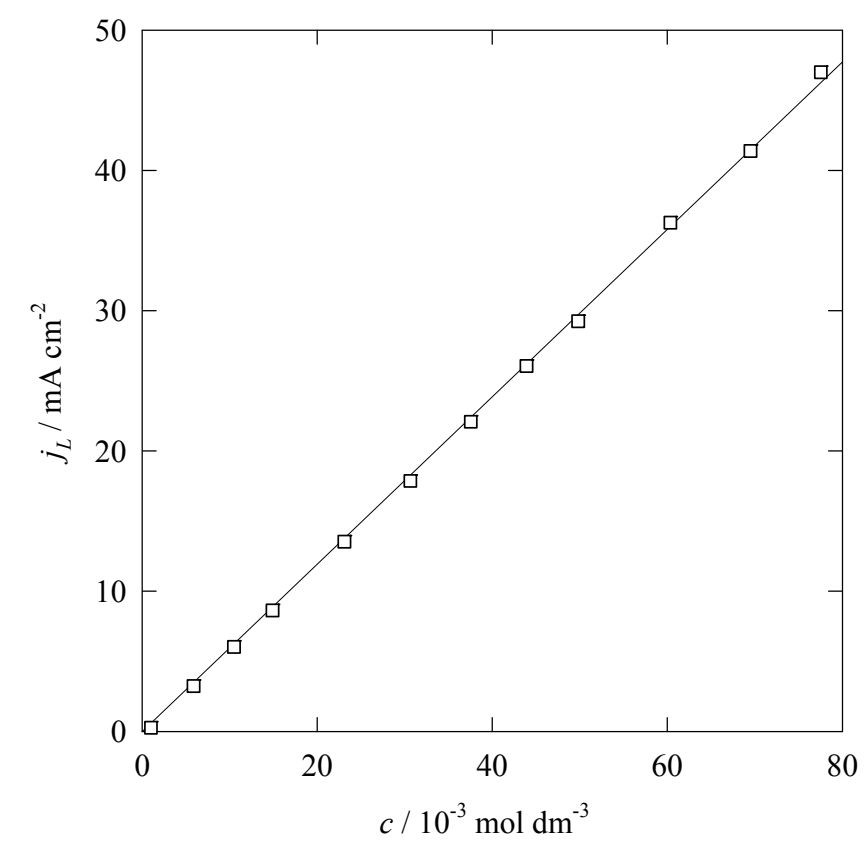

c)

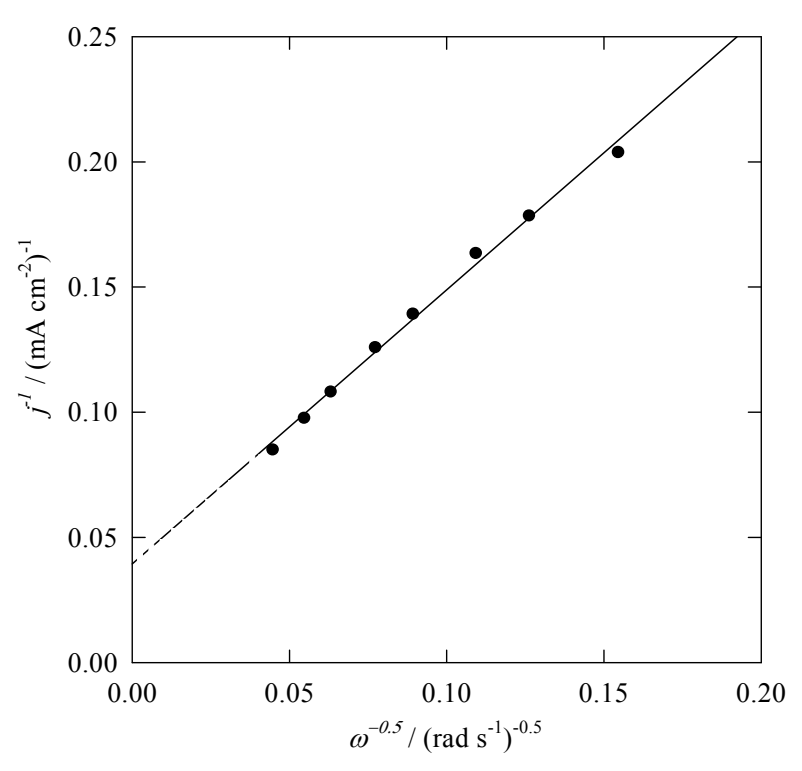

d)

Figure 3 
Figure 4

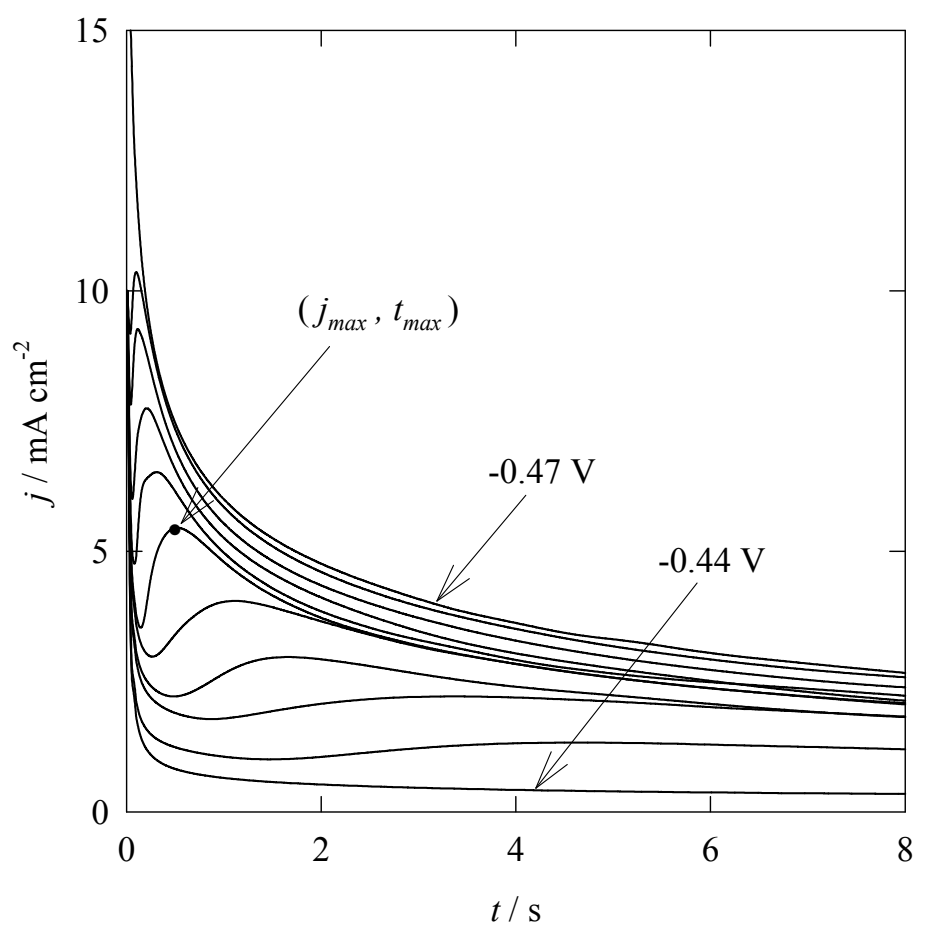

a)

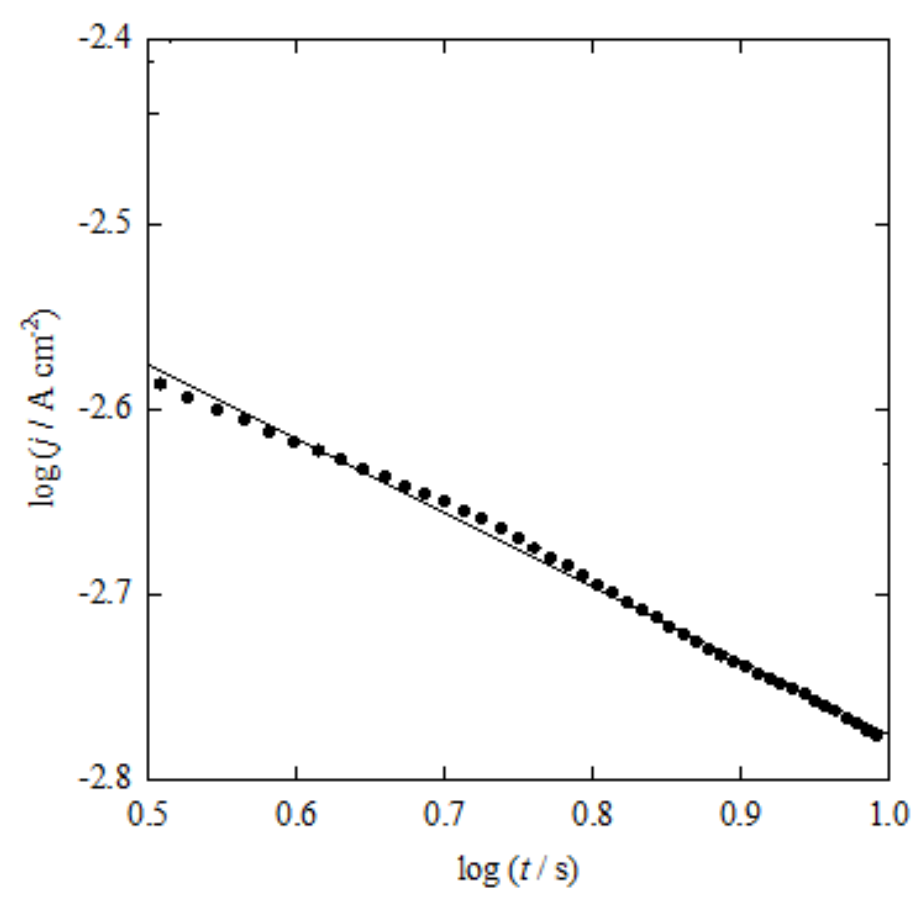

b)

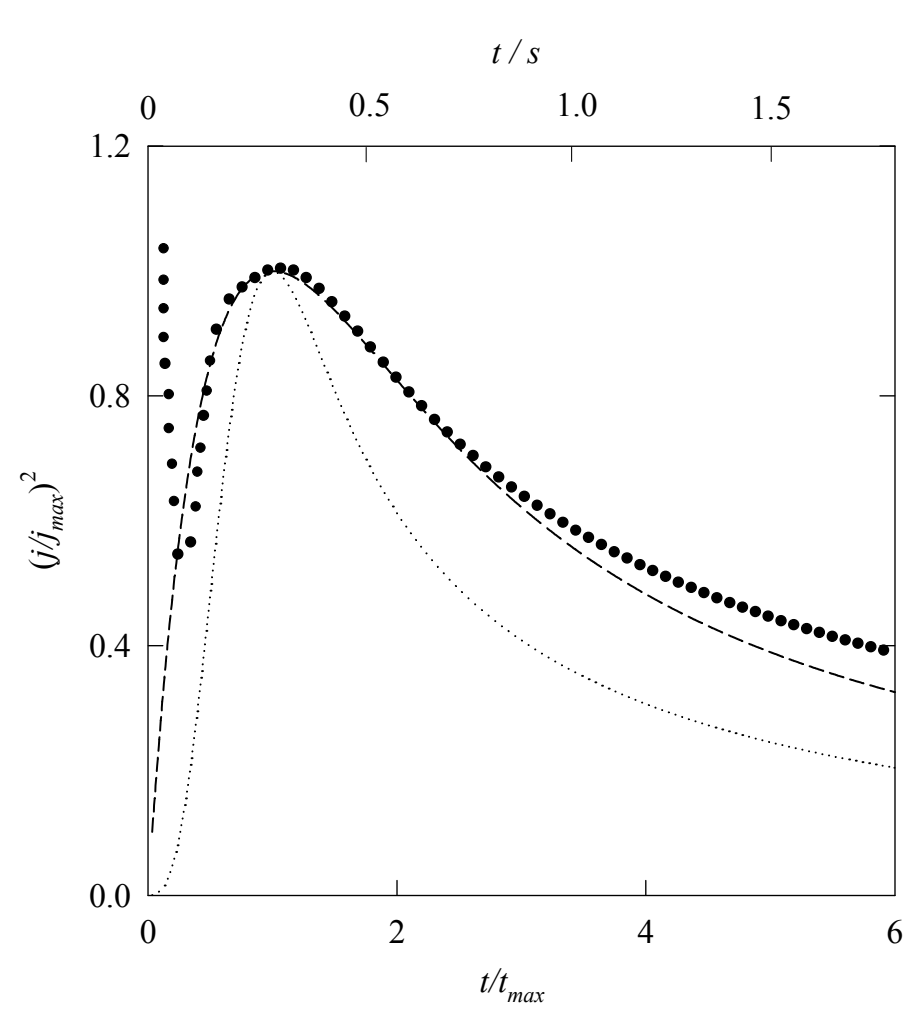

c)

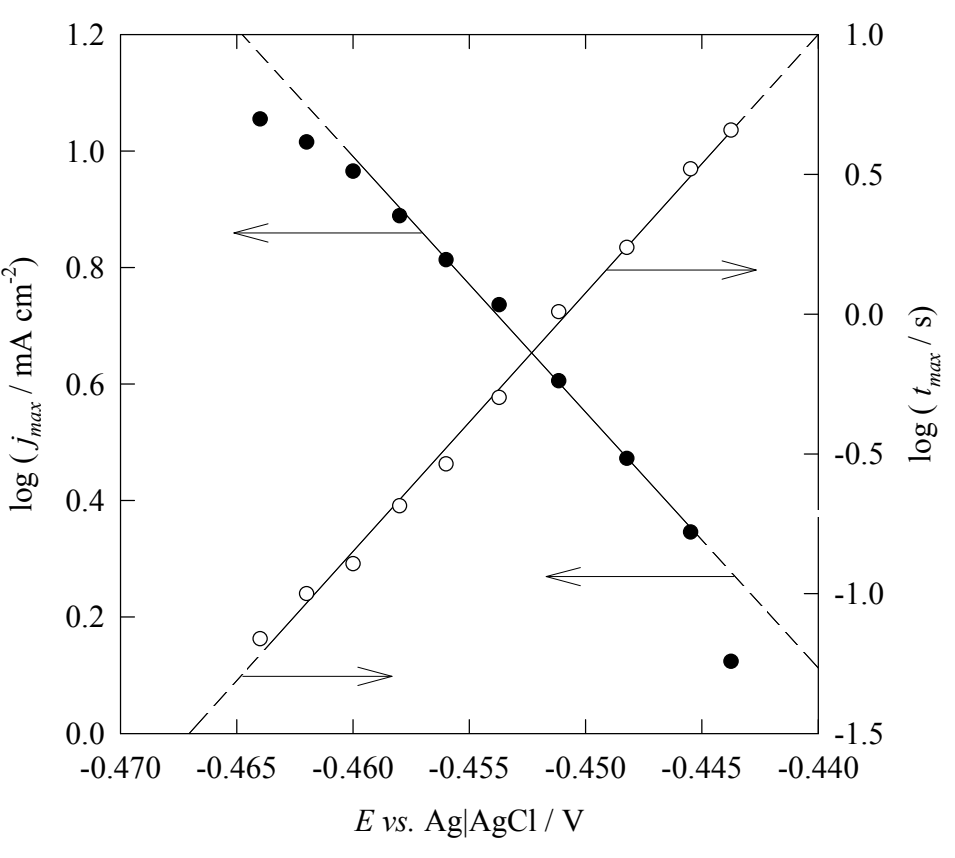

d) 
Figure 5

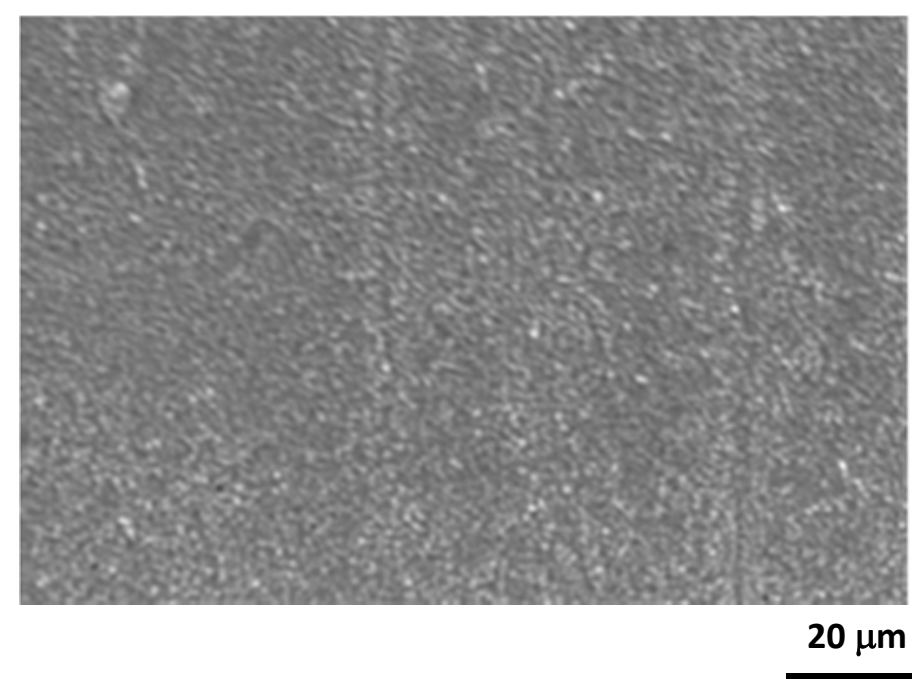

Figure 5a)

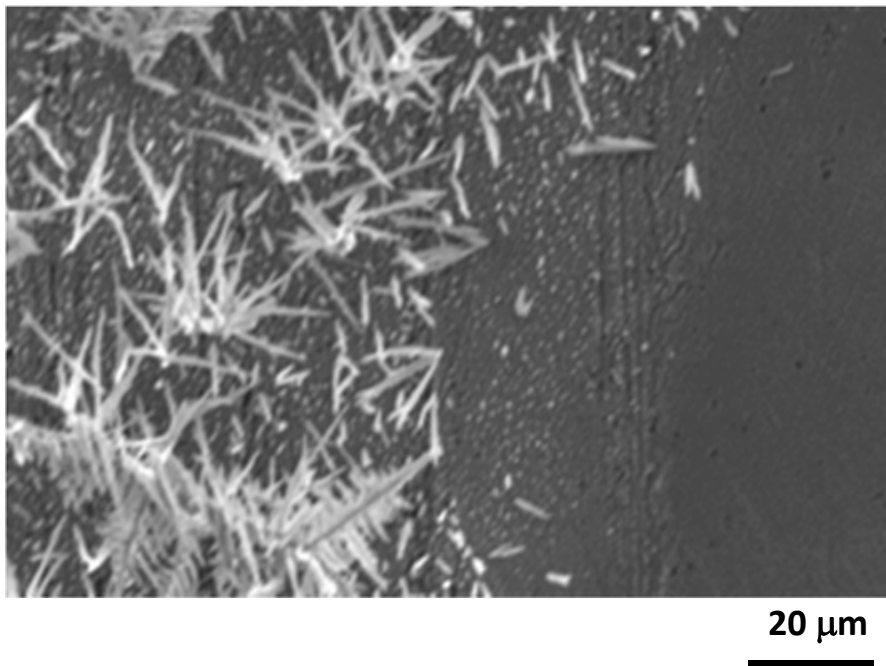

Figure 5b) 


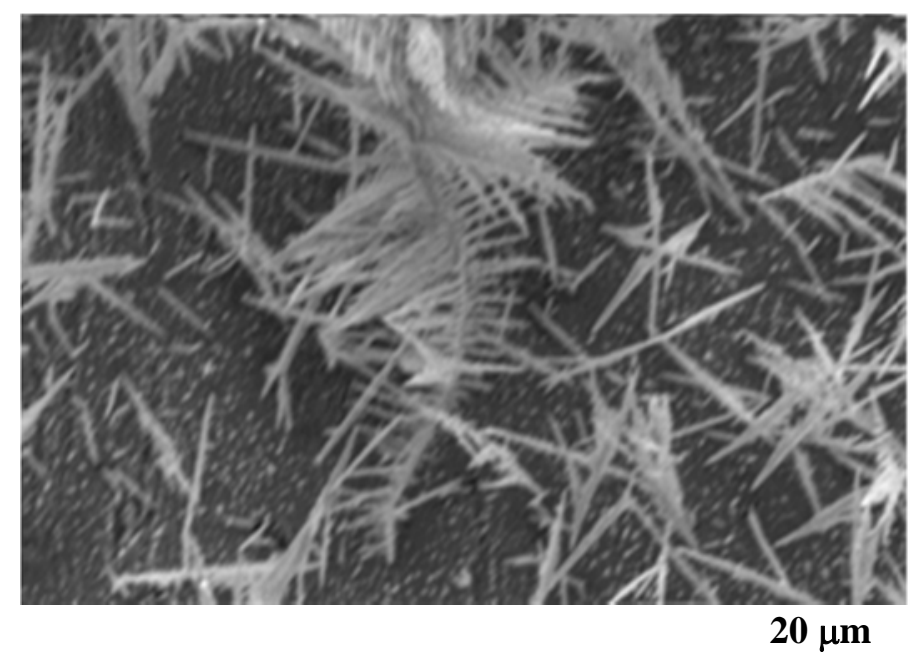

c)

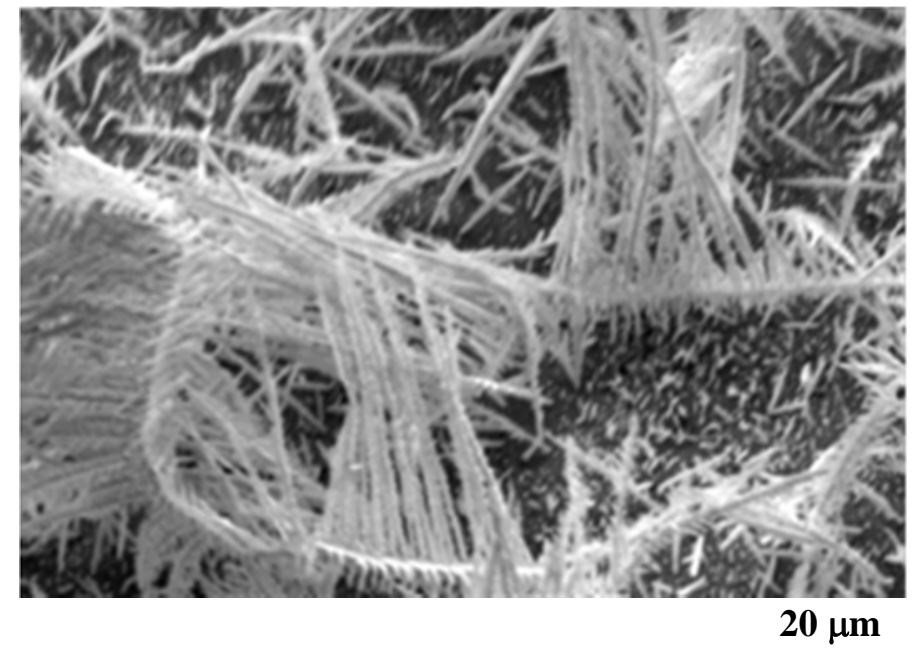

d)

Figure 5 


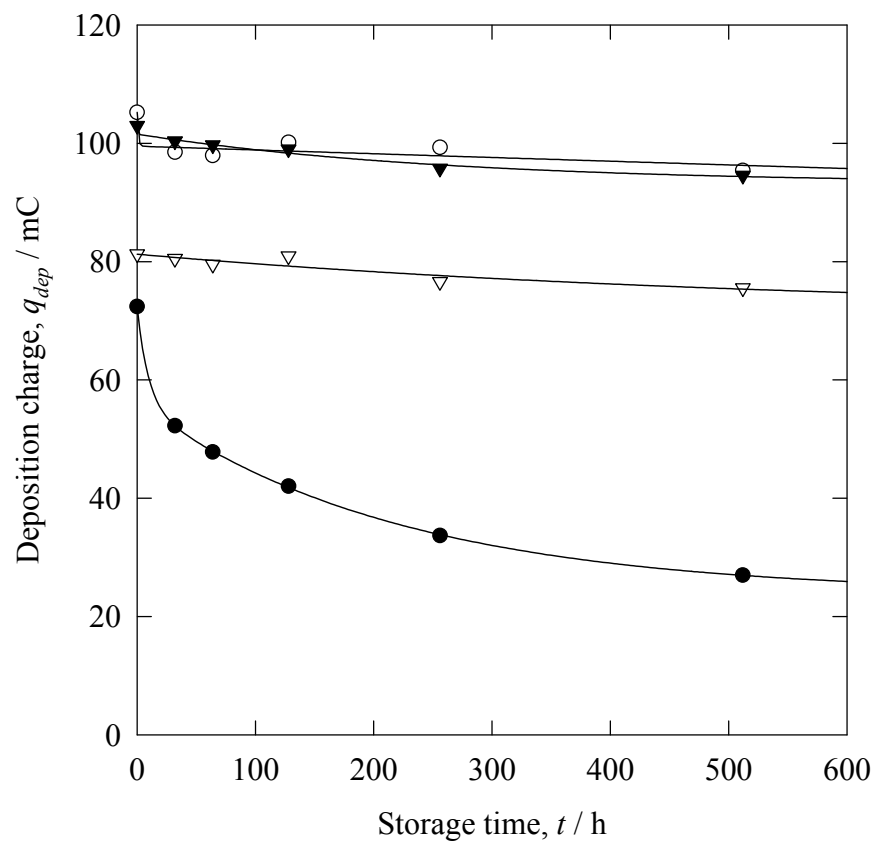

a)

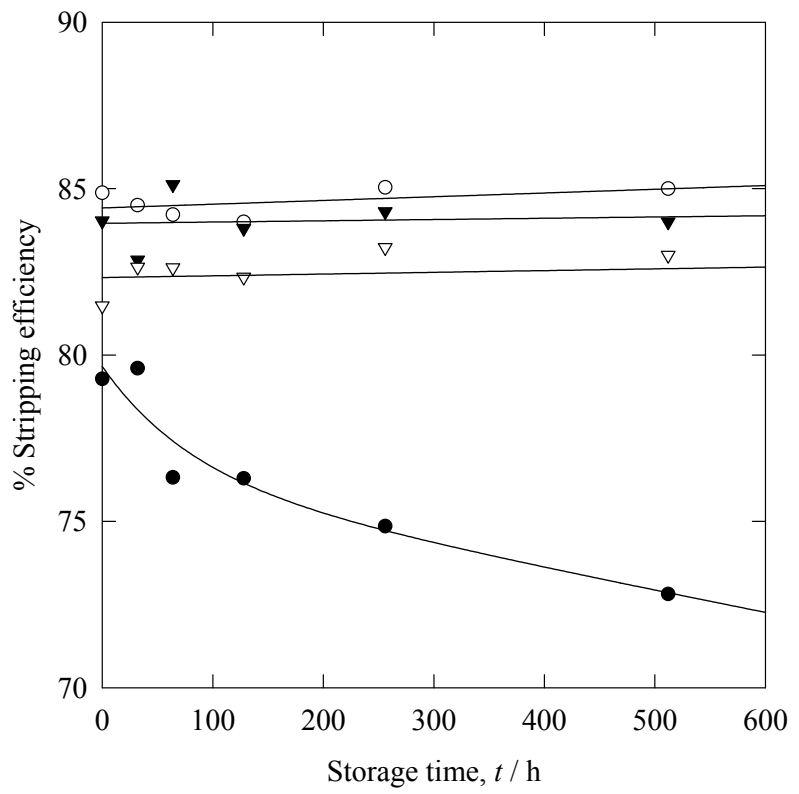

b)

Figure 6 


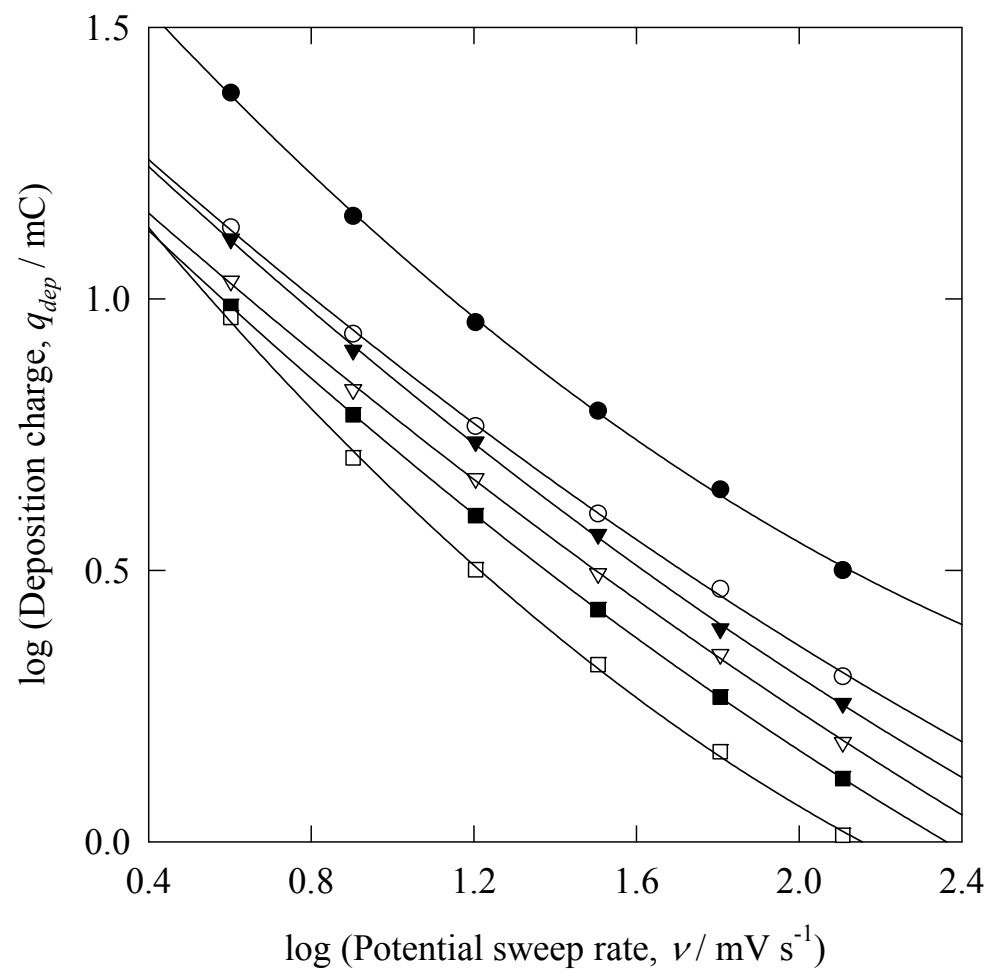

a)

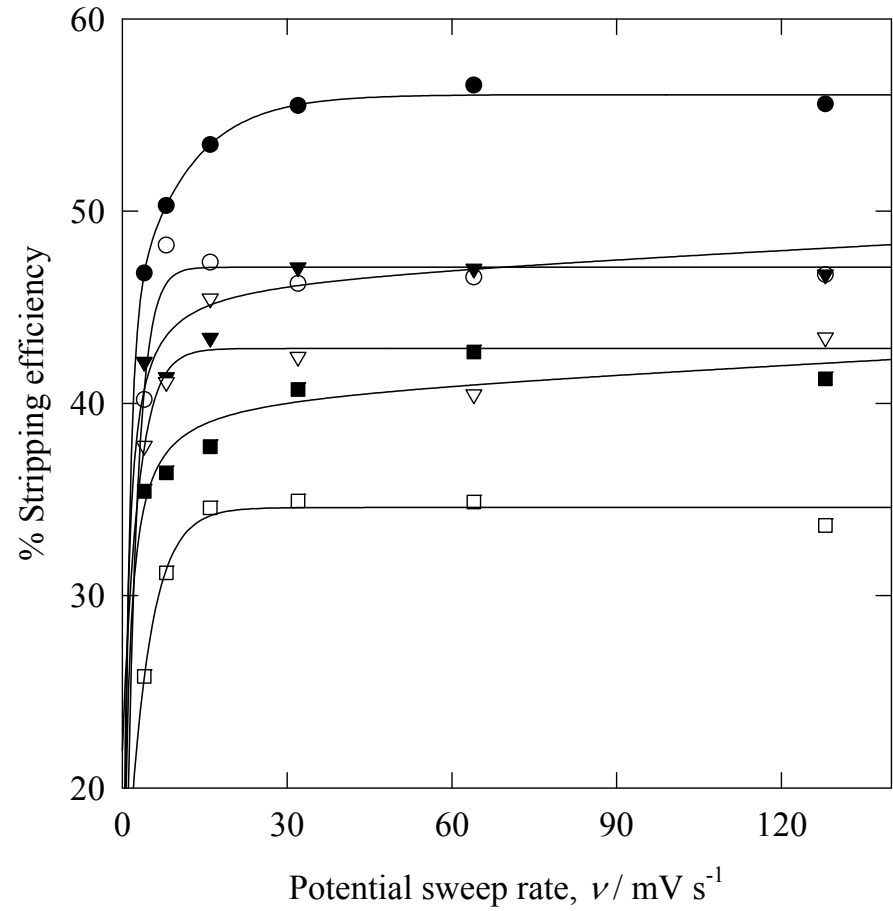

b)

Figure 7 


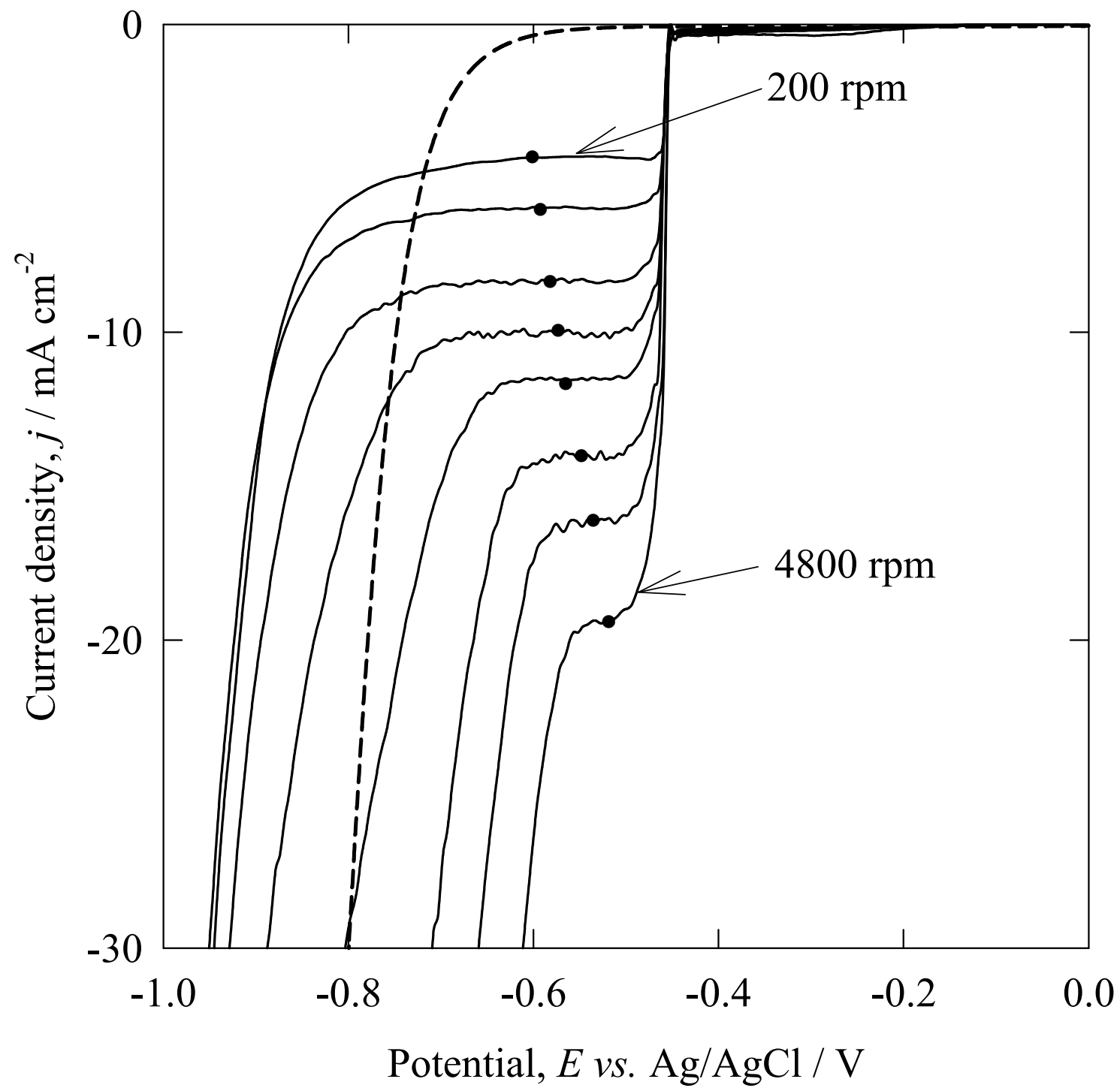

Figure 8 


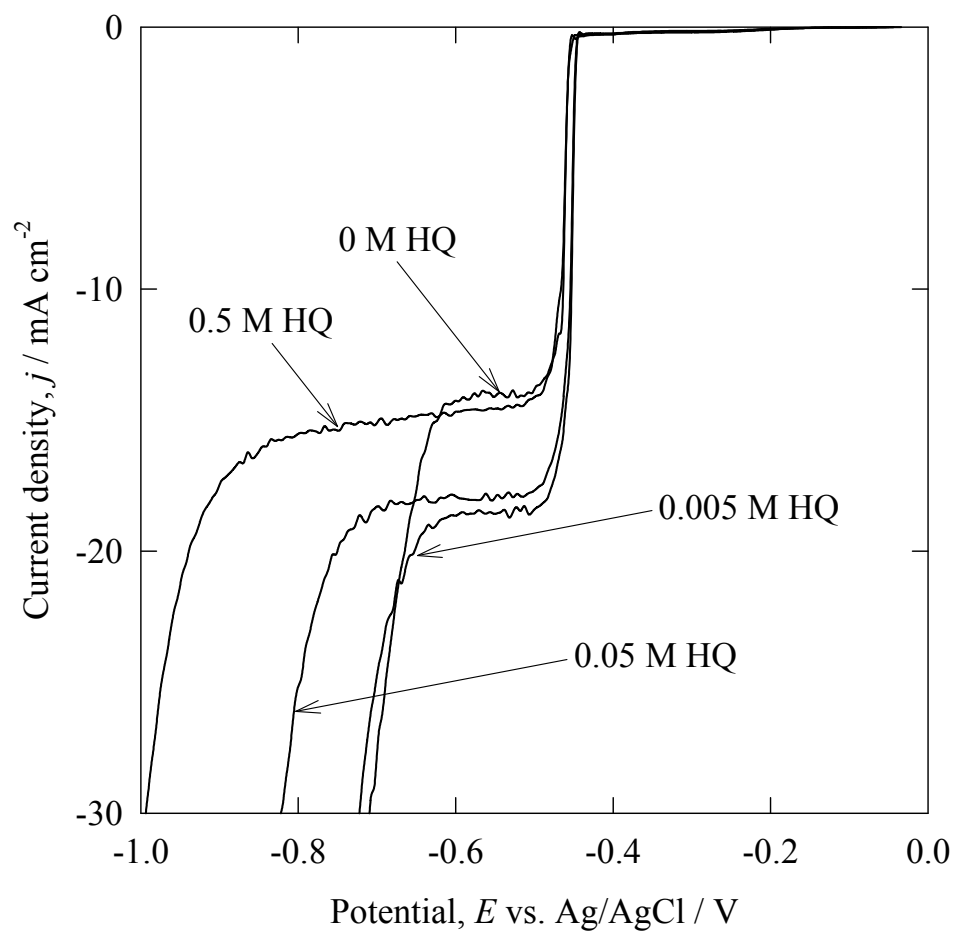

a)

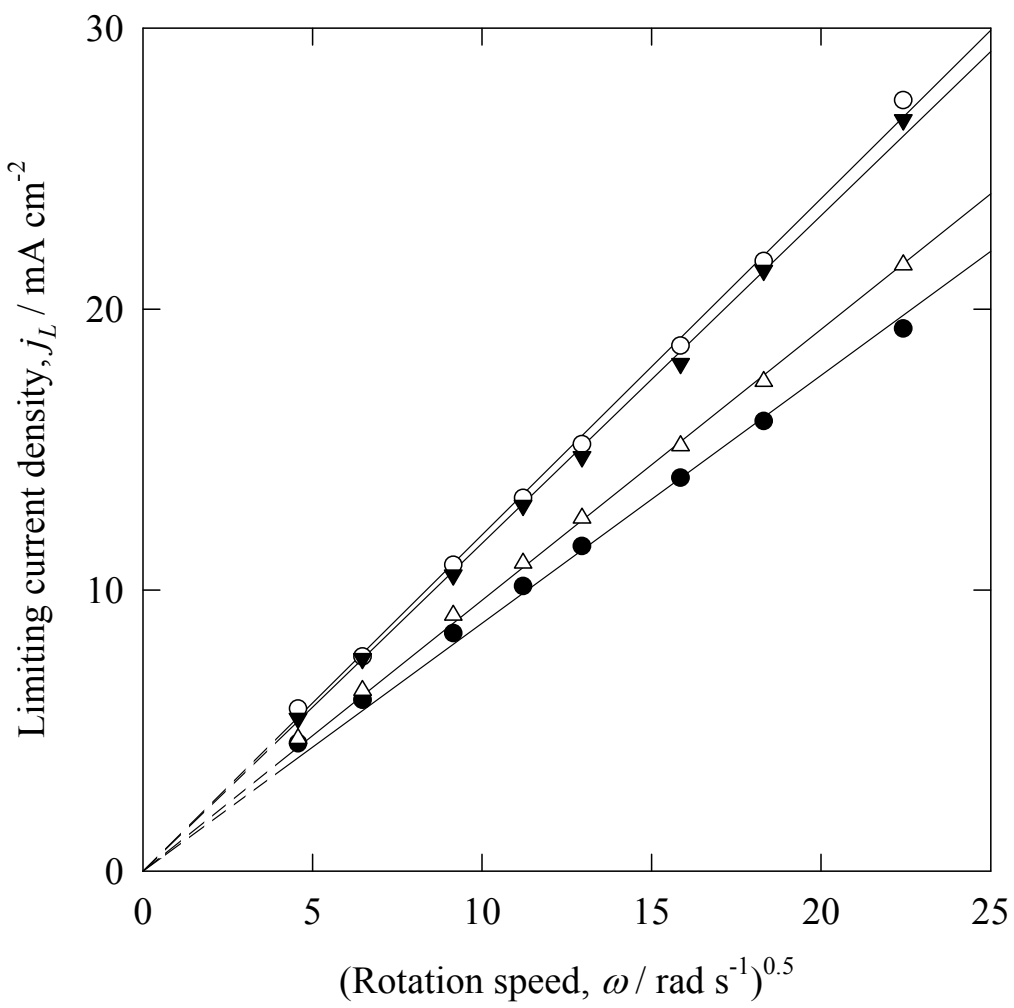

b)

Figure 9 


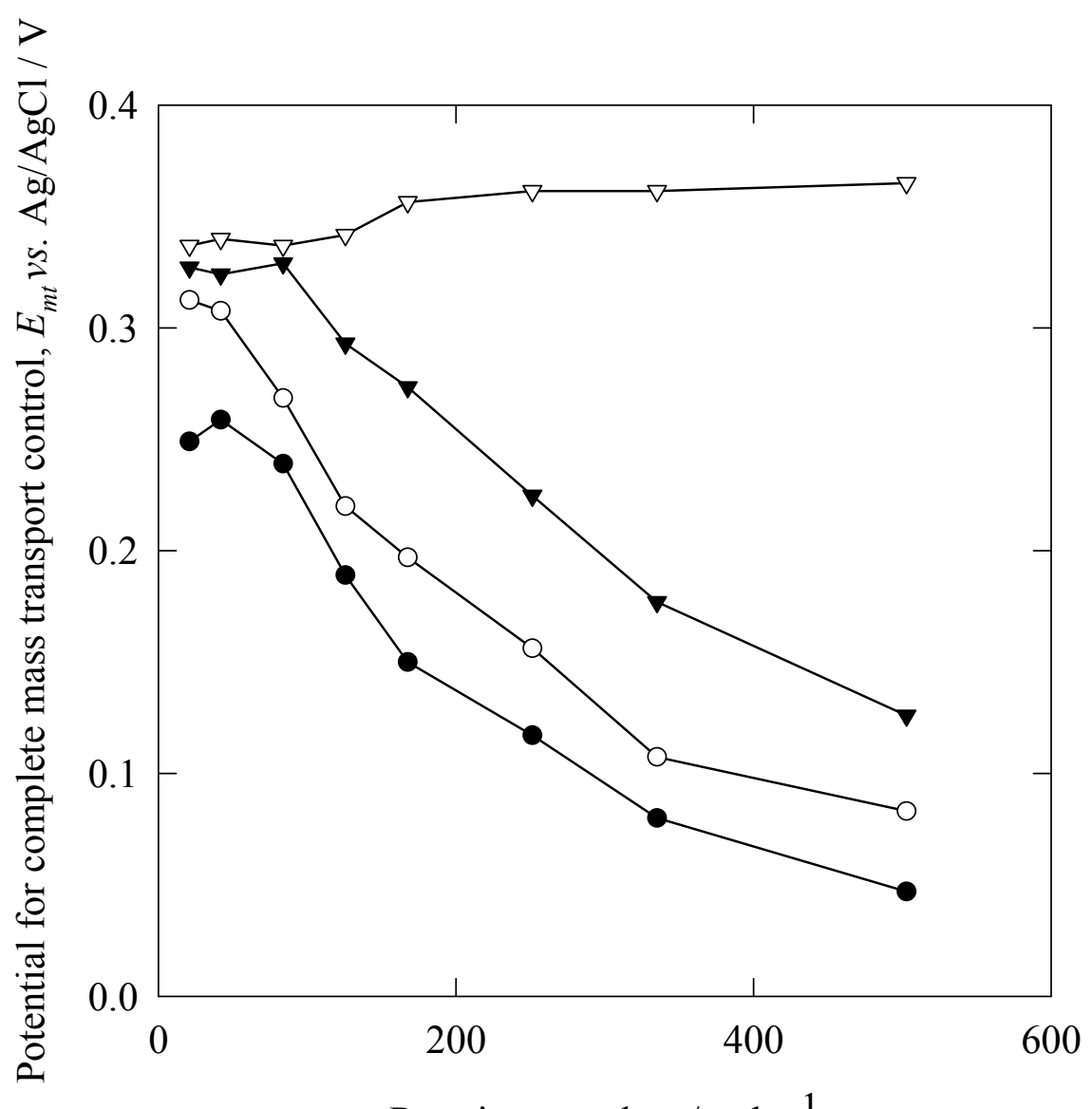

Rotation speed, $\omega / \operatorname{rad~s}^{-1}$

a)

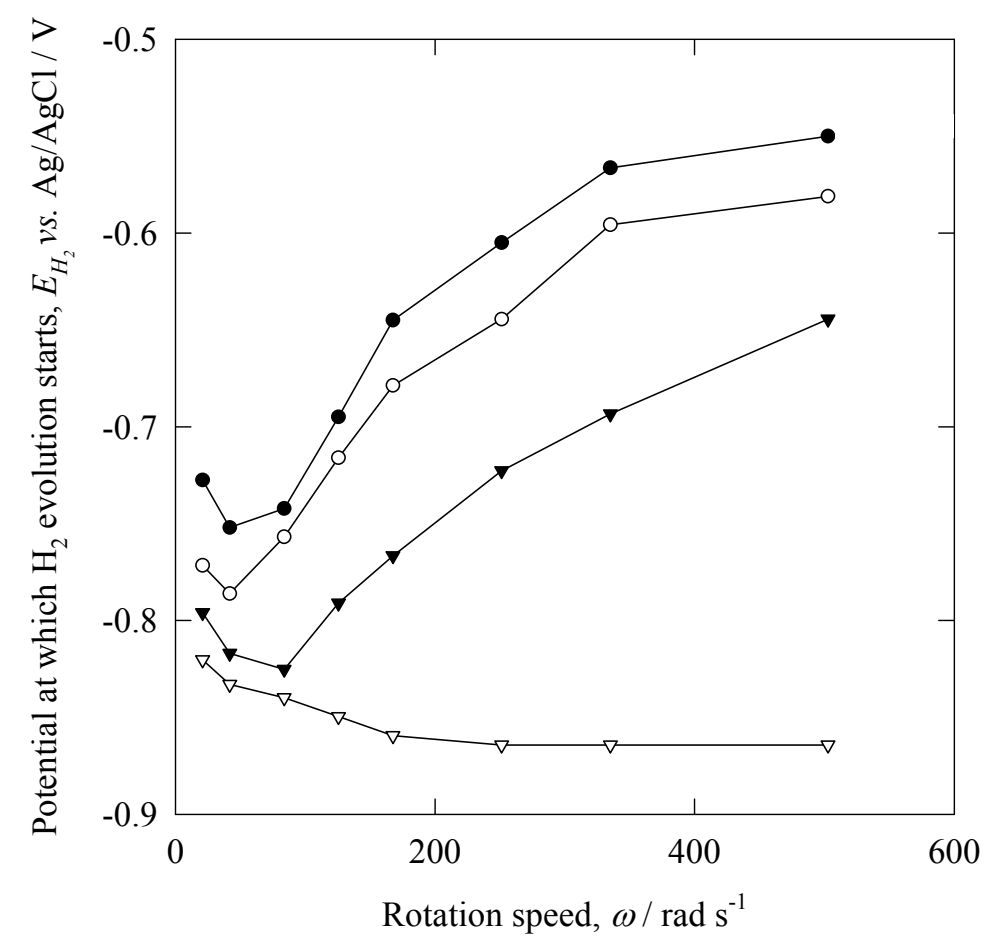

b)

Figure 10 


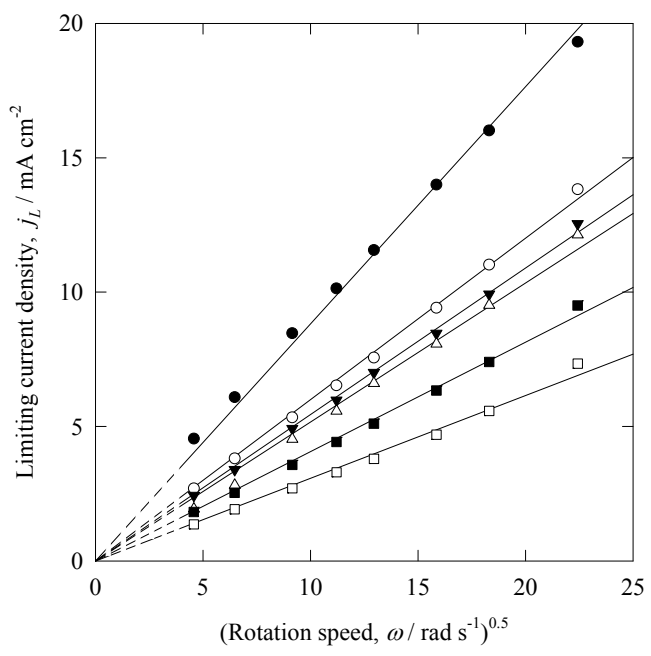

a)

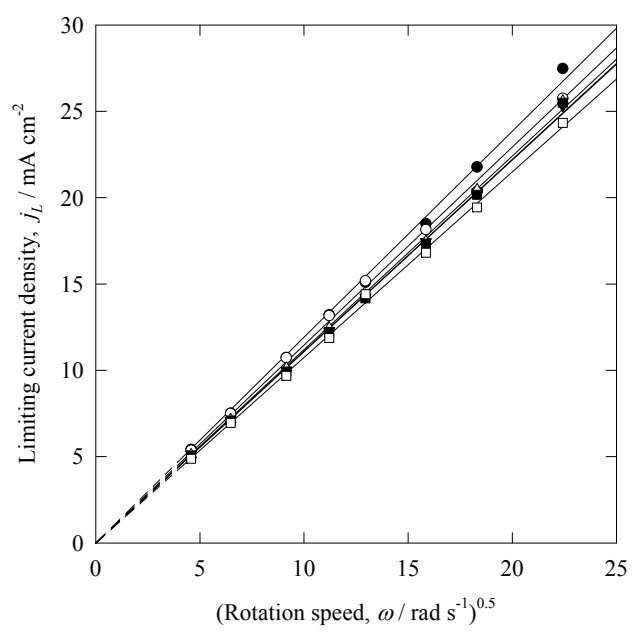

b)

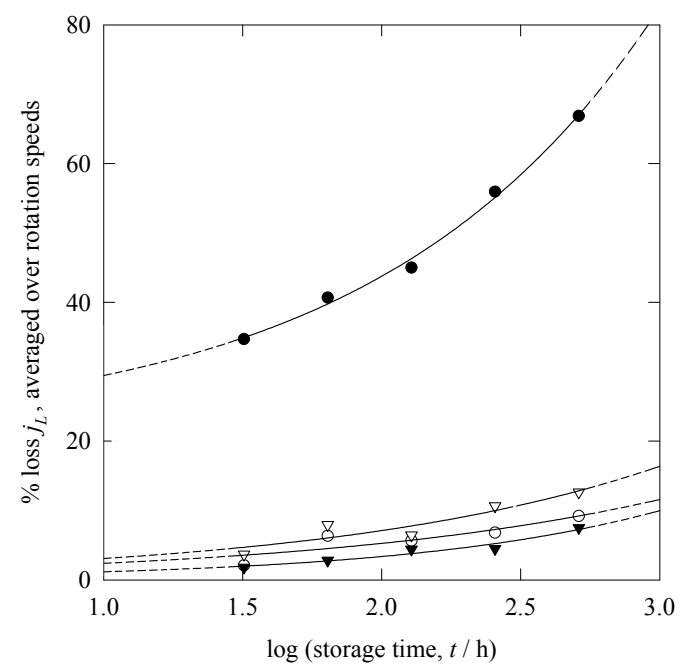

c)

Figure 11 


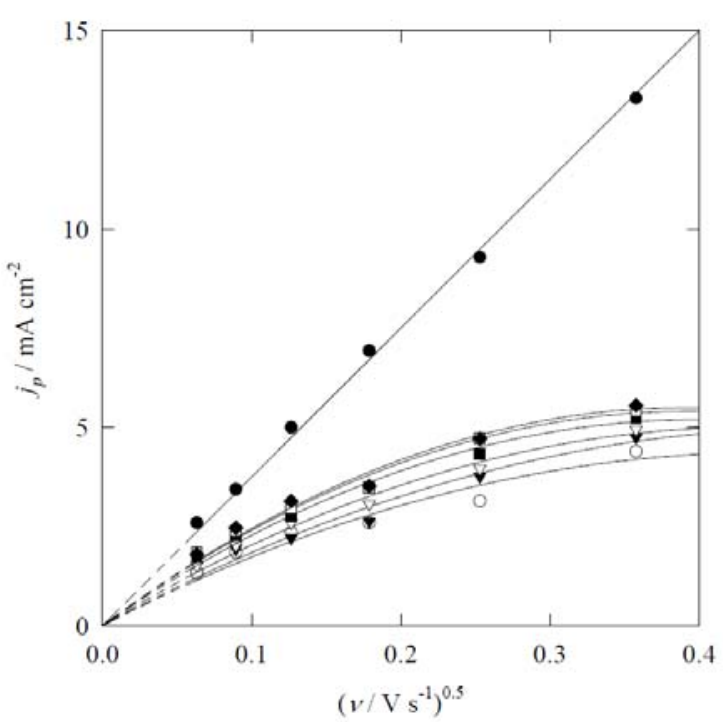

a)

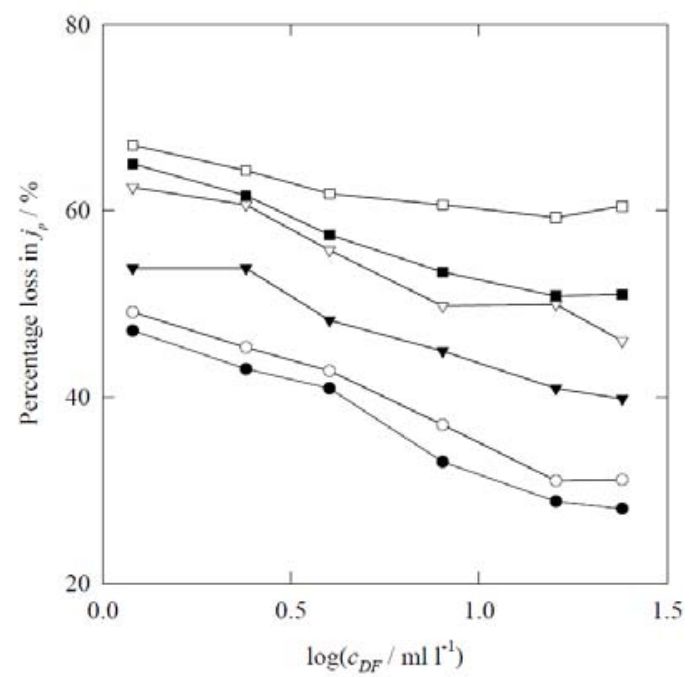

b)

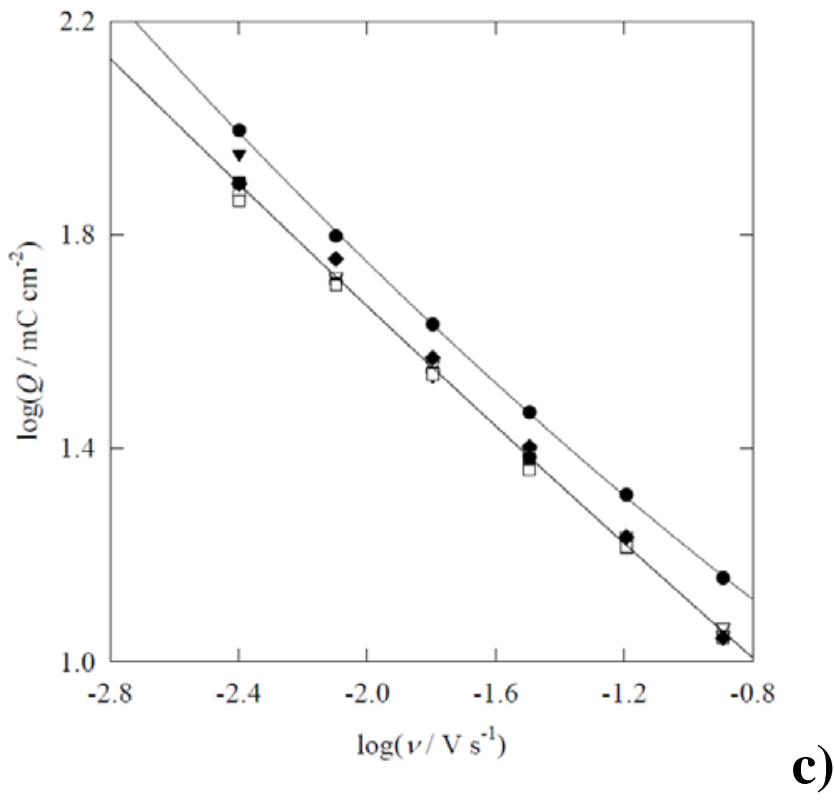

Figure 12 